\title{
The Effects of the Human Voice on the Behavioral Indicators of Stress in Dogs Housed in an Animal Shelter
}

Juliana M. Hypes

Follow this and additional works at: https://researchrepository.wvu.edu/etd

\section{Recommended Citation}

Hypes, Juliana M., "The Effects of the Human Voice on the Behavioral Indicators of Stress in Dogs Housed in an Animal Shelter" (2015). Graduate Theses, Dissertations, and Problem Reports. 5849. https://researchrepository.wvu.edu/etd/5849

This Thesis is protected by copyright and/or related rights. It has been brought to you by the The Research Repository @ WVU with permission from the rights-holder(s). You are free to use this Thesis in any way that is permitted by the copyright and related rights legislation that applies to your use. For other uses you must obtain permission from the rights-holder(s) directly, unless additional rights are indicated by a Creative Commons license in the record and/ or on the work itself. This Thesis has been accepted for inclusion in WVU Graduate Theses, Dissertations, and Problem Reports collection by an authorized administrator of The Research Repository @ WVU. For more information, please contact researchrepository@mail.wvu.edu. 
The Effects of the Human Voice on the Behavioral Indicators of Stress in Dogs Housed in an Animal Shelter

\author{
Juliana M. Hypes \\ Thesis submitted to the \\ Davis College of Agriculture, Natural Resources and Design \\ at West Virginia University \\ in partial fulfillment of the requirements \\ for the degree of \\ Master of Science \\ in \\ Animal Physiology \\ Hillar Klandorf, Ph.D., Chair \\ Jeryl C. Jones, DVM, Ph.D \\ Ida Holaskova, Ph.D \\ Department of Animal and Nutritional Science \\ Morgantown, West Virginia \\ 2015 \\ Keywords: animal shelter, stress, behaviors, dogs \\ Copyright (C 2015 Juliana M. Hypes
}




\begin{abstract}
The Effects of the Human Voice on the Behavioral Indicators of Stress in Dogs Housed in an Animal Shelter
\end{abstract}

Juliana M. Hypes

Animal shelters are very stressful environments for the animals housed there. Dogs that live in shelters have been observed exhibiting stress-related behavior such as barking, pacing, aggression and fear related behaviors such as cowering. Behaviors of this nature are off-putting to prospective adopters. To combat this problem, shelters are using different types of behavioral programs to reduce stress in the kennels. One such program involves human volunteers reading to the dogs. The aim of this study was to determine if listening to the human voice could reduce the expression of stress-related behaviors in shelter dogs. In order to establish the human voice as the primary stimulus, three different audiobook recordings were utilized. Recordings were narrated by a British male, an American male and an American female. Twenty dogs were used in the experiment, ten dogs in the experimental group and ten dogs in the control group. A crossover AB/BA design was used where each group of ten dogs was exposed to all three recordings for 45 minutes at various times during the study. Throughout the 45 minute sessions and at 5 minutes intervals a behavioral observation was recorded for each dog via the shelter cameras. The dogs that were exposed to the recordings displayed relaxed behaviors $73.61 \%$ of the time and stress related behaviors $26.39 \%$ of the time. The dogs that were exposed to no audio recording displayed relaxed behaviors $24.07 \%$ of the time and stressed behaviors $75.92 \%$ of the time. No significant differences were observed when the dogs were exposed to the different accents or vocal pitch (male vs. female) of the narrators $(\mathrm{P}=0.05)$. These results support the usage of this low-cost tool in animal shelters to promote the expression of more relaxed kennel behavior. Ultimately the improved shelter environment could lead to an increase in adoption rates. 


\section{To my parents}

\section{Wayne and Jessica Hypes}

Without whom I never would have made it 


\section{Acknowledgements}

I would like to thank my thesis advisor Dr. Hillar Klandorf for helping me through this process. I would like to thank my committee members Dr. Jeryl Jones and Dr. Ida Holaskova for all their help and support. Finally I would like to thank the administration and staff of the Kanawha Charleston Humane Association for allowing me to conduct this research at their facility. 
Table 1. Ethogram of Behaviors of Kenneled Shelter Dogs....

Table 2. Descriptive Statistics of Observed Behaviors .30

Table 3. Matched t-test to Compare Total Number of Nonstress-related and Stress-related Behaviors in the Audio vs. Control Groups .31

Table 4. Wilcoxon Signed Rank test for Differences in Vocalizations for

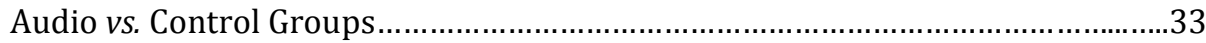

Table 5. Wilcoxon/ Kruskal-Wallis Test for Differences in Vocalizations

for Audio vs. Control Groups .33

Table 6. Matched T-test for Vocalizations by Voice Variables..... 35

Table 7. Matched t-test to Compare Total Number of Stress-related Movements in Audio vs. Control Groups. 37

Table 8. Wilcoxon Signed Ranked Test for Movement Type by Voice

Variable .40

Table 9. Matched T-test for Experimental Units by Treatment .43 
Figure 1: Behavioral Observation Collection Method

Figure 2: Cross-over Design. .25

Figure 3.Behaviors Observed When Exposed to Auditory Stimulus .28

Figure 4. Nonstress-related Behaviors Observed When Exposed to Auditory

Stimulus. .29

Figure 5. Types of Behaviors Observed in Dogs for Audio vs. Non-Audio Stimulus

Figure 6. Matched Pairs Difference for Nonstress-related and Stress-related

Behaviors for Audio vs. Non-Audio. .32

Figure 7. The Average Number of Vocalization Responses by Treatment Type .34

Figure 8. Average Vocalization Response in Audio Group by Voice Variables .36

Figure 9. Average Number of Movement Types by Treatment .38

Figure 10. Average Number of Movement Types by Treatment in Bar Graph Form.. . .39

Figure 11. Average Number of Movement Types in Audio Group by Voice Variable. .41

Figure 12. Average Number of Movement Types by Voice Variable in Bar Graph

Form. .42

Figure 13. Average Number of Each Behavior Type per Experimental Units by

Treatment. .44 
Figure 14. Behaviors Observed in Individual Subjects when Exposed to Audiobook

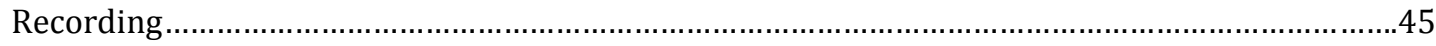

Figure 15. Behaviors Observed in Individual Subjects without Audio Recording ..........................46 


\section{Table of Contents}

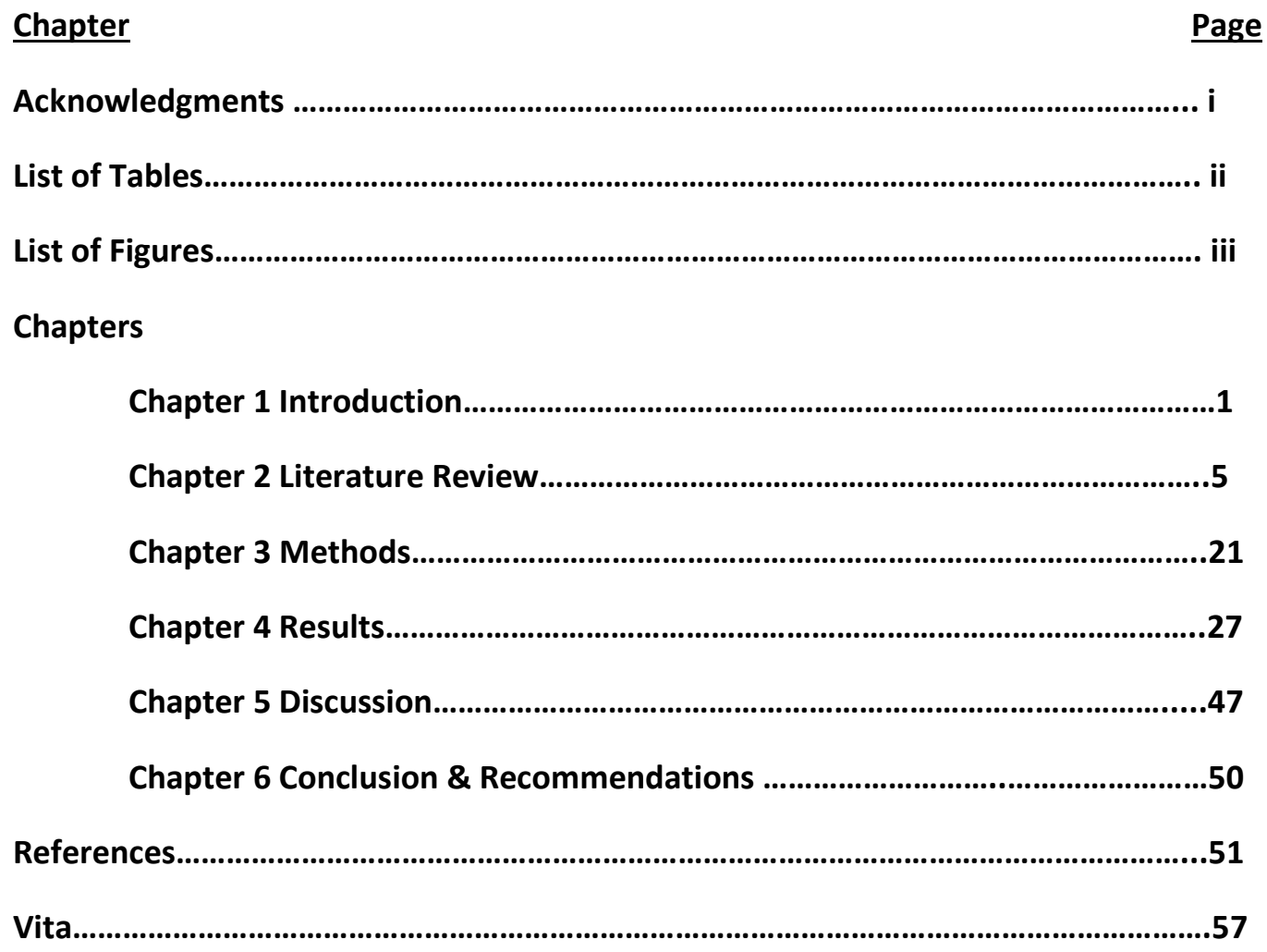




\section{Chapter 1}

\section{Introduction}

Every year 6-8 million dogs and cats enter animal shelters in the United States, of which approximately 3-4 million are euthanized (Maddie's Fund 2013). These staggering statistics illustrate a problem that needs to be addressed. The financial and emotional strain that pet overpopulation causes animal shelters is a rising issue that is leading many individuals to call for change. As an effort to decrease the number of animals euthanized shelters are attempting to adopt a no-kill philosophy. A no-kill shelter is defined as any animal shelter that only euthanizes animals that are unhealthy and untreatable (Maddie's Fund 2000). In order for a no-kill animal shelter to be successful there must be an increase in pet adoptions to off-set the decrease in euthanasia being used as population control. According to the American Humane Association, "Seventeen million Americans acquire a new pet each year, but only 3.5 million adopt from an animal shelter" ("Pet Overpopulation" 2013). If every person adopted an animal from a shelter there would be, technically speaking, no more homeless pets.

Over the years there have been several national campaigns to help encourage pet adoption, most notably Blue Buffalo Home for the Holidays and Pedigree's Adopt a Dog ("Blue Buffalo Home 4 the Holidays Pet Adoption Campaign" 2015; "The PEDIGREE® Feeding Project" 2015) Even with this increased awareness the majority of people still decide not to adopt (Maddie's Fund 2013). This is partially due to the widely held belief that animals in shelters have behavioral problems or are "damaged goods" (Maddie's Fund 
2013). When prospective adopters visit animal shelters they are often met with dogs that jump, bark, lunge, cower or even express aggression in their kennels (Maddie's Fund 2013). These behaviors in dogs are brought about mainly by the excessive kenneling and lack of mental stimulation that most of them experience while in the shelter (Wells and Hepper 2000). As animals, particularly dogs, are generally held for longer periods of time at no-kill facilities these behaviors are exacerbated. This has resulted in many dogs being diagnosed with kennelitis. Kennelitis is defined as, "Social maladjustment towards humans as the result of being kenneled for an extended period of time without proper mental and physical stimulation" (Kennelitis 2007). Behaviors associated with this disorder include: spinning, jumping, excessive barking, in-kennel aggression and other stress related behaviors (Kennelitis 2007). This condition not only decreases a dog's chances of being adopted it also increases the risk of the dog becoming so aggressive that they become unadoptable and must be humanly euthanized. To curb this development shelters must attempt to get dogs adopted out quickly. In order to achieve this goal it is imperative to allow potential owners to see the animals in a more relaxed state. To accomplish this and to help prevent kennelitis, animal shelters need to provide some sort of stimulation to keep the animals engaged during their stay.

As more research has shown the detrimental effects that excessive kenneling can have on dogs, shelters have attempted to decrease the level of stress that animals suffer from in order to improve their wellbeing and encourage adoption. Many shelters have taken a leadership role by implementing their own programs that aim to reduce stress and improve the animal's behavior around potential adopters. A new program that has gained some popularity involves volunteers reading to dogs (Backus 2013). The reading program 
started out as an initiative to help children better their reading skills and to allow the dogs some company (Backus 2013). The program revolved around the notion that children would feel less self-conscious about reading in front of animals. While the children's reading skills improved volunteers realized that the dogs used in the program were behaving in a much calmer manner once the reading sessions were complete (Backus 2013). This led to the belief that programs of this nature could be used to reduce the amount of stress that animals experience in the shelter environment. Furthermore research has looked into audiobook recordings and found that they can also modify the behavior of dogs (Lacey 2012). If audiobook recordings could be used to increase relaxed behaviors at times when volunteers are not able to read to the dogs this could be beneficial for animal shelters.

The main objective of the current research project was to determine whether dogs in animal shelters exhibit fewer behavioral indicators of stress when exposed to recordings of the human voice. A secondary objective was to determine whether accents or vocal pitch (male vs. female) have an effect on the behavioral responses of the dogs. The vocal pitch is important because studies have shown that dogs consider a higher pitch to be equivalent to an excited bark and lower voices to be comparable to a growl (Hoffman 1999). If a recording of the human voice could provide sufficient stimulation to reduce the expression of stress-related behaviors, then this could be a low-cost tool that shelters could use in the future to decrease stress and hopefully increase the number of adoptions. 


\section{Research Objectives}

1. Does the sound of a recorded human voice increase the number of nonstress-related behaviors observed in shelter dogs?

2. Do different human accents have different impacts on the types of behaviors (stress related vs. nonstress-related) observed in shelter dogs?

3. Does the vocal pitch (man vs. woman) have an impact on the types of behaviors (stress related vs. nonstress-related) observed in shelter dogs?

\section{Hypotheses}

1. Dogs in the experimental group will exhibit a higher amount of nonstress-related behaviors after listening to forty-five minutes of a recorded audiobook as compared to the control group.

2. There will be no difference in the dogs' preference for accents.

3. Dogs will exhibit more nonstress-related behaviors when exposed to the female voice as compared to the male voice due to vocal pitch associations (i.e. higher voice $=$ excited barking; lower voice $=$ growl) . 


\section{Chapter 2}

\section{Literature Review}

Animal shelters generate a stressful environment for dogs (Chappell 2009). The noise levels, lack of mental stimulation, lack of exercise, and exposure to many different kinds of animals can increase unwanted behaviors in dogs. Recently scientists have initiated programs to reduce stress and improve the overall wellbeing of our companion animals (Biele, 2012; Wells, Graham, \& Hepper 2005; Coppola et al., 2012; Hennessy 2006; Herron 2014; Kogan, Schoenfeld, \& Simon 2012; Normando 2009; Pullen 2012; Shiverdecker 2013). The goal of most research centered on animal welfare in shelters is to provide solutions to behavior problems in the most cost effective manner.

\section{Behaviors that Affect Adoption in Shelter Dogs}

Behavioral indicators of stress can have an impact on a dog's chance of getting adopted. A recent study looked at the behaviors exhibited by dogs while in a kennel and the effect it had on their length of stay at the animal shelter (Protopopova et al., 2014). The investigators videotaped 289 dogs for one minute daily throughout their stay at the shelter. They found that certain behaviors correlated with a longer stay at the shelter. Behaviors such as leaning or rubbing against the enclosure's wall, facing away from the front of the kennel and standing, correlated with an increase in the dog's shelter stay by an average of 15 days. This study helped highlight how stress-related behaviors such as facing away from the kennel door can decrease the likelihood of a dog being adopted. 
If dogs expressed more desirable behaviors such as sitting and lying down would this decrease their length of time at the shelter? A recent study conducted in 2014 investigated the effect of food enrichment activities and cage behavior training on the behavior of shelter dogs and their adoption rate (Herron 2014). The study used 107 dogs that were divided into two groups: an experimental group that was exposed to enrichment activities and a control group. The behavioral observations were recorded on the first day the dogs were on the adoption floor and on day 3 by blinded observers. They found dogs that were exposed to the enrichment activities exhibited higher numbers of desirable behaviors such as sitting and lying down. The experimental group also showed a decrease in barking and jumping in the kennel. The study did not find a significant difference in adoption rates between the groups. This study provided evidence of the importance of enrichment activities for improving the welfare of shelter dogs. While the study found no link between a higher amount of desirable kennel behaviors and adoption rates, the researchers stressed that other factors such as breed, age and sex could have affected adoption rates and these were variables that could not be controlled for in the current study.

\section{Behavioral and Physiological Indicators of Stress in Shelter Dogs}

How can you tell if a dog is stressed? Researchers from the Netherlands wanted to answer that very question. The goal of their study was to determine behavioral parameters to identify stress in dogs (Beerda 1998). They did this by subjecting ten dogs to six different aversive stimuli: sound blasts, short electric shocks, a falling bag, an umbrella opening and two different forms of restraint. They recorded the dogs' behavioral 
responses during the one minute exposure to the stimuli. They also measured the dog's salivary cortisol levels and heartrate to support the interpretation of their behavioral data (Beerda 1998). The researchers found that when exposed to the sound blasts, shocks and falling bag the dogs exhibited a very low body posture and also showed an increase in cortisol levels. The other three stimuli did not affect the dogs' cortisol levels but did increase certain body movements including: body shaking, yawning, restlessness and lowering of the body. The heartrate was found to increase nonspecifically for each stimulus and thus was not able to be interpreted with regard to stress. The study concluded that intense stress in dogs may be indicated by a very low body posture, and behaviors such as yawning, restlessness, oral behaviors and moderate lowering of the body may indicate moderate stress. Being able to identify the behavioral indicators of stress in dogs is important to animal shelter workers as it can alert them to welfare problems.

Housing dogs in kennels for an excessive amount of time can not only lead to deterioration in behavior but also physiological problems. A study conducted in England looked at the effect of acute and chronic stress on canine physiology (Chappell 2009). They looked at cortisol levels, appetite, weight gain, body condition score, respiratory rate and fecal quality in 58 healthy new arrivals to an animal shelter. The dogs were monitored during their first two weeks of kenneling in the isolation unit. The researchers found that there was an overall increase in urinary cortisol levels, significant periods of decreased appetite, idiopathic diarrhea, decrease in body condition score, high incidence of rapid breathing and widespread weight loss. These conditions were concluded to be brought on by chronic stress due to excessive kenneling. 
Another study looked at the behavioral and physiological responses of shelter dogs when they were confined in either grouped (more than 2 dogs) or paired housing (only 2 dogs (Dalla 2013). The dogs were exposed to both test conditions. Salivary cortisol samples were collected and behavioral observations were recorded to act as welfare indicators. The researchers found that dogs in paired housing exhibited far fewer social and exploratory behaviors as compared with the group housing. The cortisol levels did not significantly vary between groups but rather varied between individual dogs. They concluded that neither type of housing decreased animal welfare but did affect the expression of certain behaviors. This study provides a different look at factors that can affect a dog's stress levels while in an animal shelter.

A recent study expanded upon the abovementioned research on stress and housing type in shelter dogs. The investigators looked at the effect of separation from a conspecific (member of the same species) on 12 shelter dogs in a pair housing situation on behavior and physiology (Walker 2014). They measured the impact of the separation by examining behavior, cognitive bias, fecal S-IgA and cortisol levels. S-IgA is an antibody that provides protection against different types of pathogens. It is used as a common marker for stress because an increase in S-IgA has been shown to be positively correlated with an increase in stress. They found that after separation dogs expressed an increase in running, grooming, circling, posture changes and stretching and a decrease in play behavior. Concentrations of IgA increased in dogs after separation but cortisol levels remained the same. There was also no difference in the cognitive bias test as dogs responded the same before and after separation to ambiguous cues. The results from this study showed that separating dogs that have been housed together can negatively impact behavior and produce an immune 
response which could be suggestive of an increase in stress. This is just another example showing how stress affects the lives of dogs housed in animal shelters.

\section{Welfare Concerns for Shelter Dogs}

Stress can and does affect dogs in animal shelters both in a physical and behavioral way. This can be concerning for individuals who care for these dogs as it brings up questions about poor welfare. The extent to which the dog's mental and physical state declines due to excessive stress and kennelitis can bring about concerns for the dog's quality of life.

A study conducted by researchers in the United Kingdom looked at the prevalence of 15 behaviors associated with poor welfare including the following: excessive barking, tail chasing, listlessness and pacing (Stephen 2005). They monitored 148 dogs daily for a maximum of 6 weeks from admittance. The observers recorded which of the 15 behaviors each dog displayed every day. They found that as the length of stay increased the proportion of dogs that paced and jumped increased as well. Behaviors such as lack of appetite and fear tended to decrease over time as the dogs became acclimated to the kennel environment. These findings suggested that dogs kept in a kennel with no enrichment could have a risk of developing behaviors associated with stress and therefore poor welfare.

Another study from the United Kingdom expanded upon the previous research and look specifically at the differences between dogs that had been in a shelter for a short period of time (under 6 months) and a long period of time (over 6 months) (Titulaer 2013). They used a range of indicators including: a judgment bias test (dog's reaction to 
ambiguous stimuli), assessment of behavior in three situations (no person present, stranger passing and stranger approaching), measurement of urinary cortisol levels and a questionnaire filled out by each dog's main caretaker. Cortisol is a hormone that is released in response to stress and anxiety by the adrenal gland and is used as a common objective marker of stress. The researchers found that the dogs did not significantly differ in the judgment bias test or behavior assessment. The urinary cortisol levels for both groups were high and varied greatly between dogs. The staff questionnaire was similar for both groups but they reported that dogs that had been there for over 6 months played less, barked more at strange dogs and were more interested in playing with objects than other dogs. They found there was no real difference between the two groups but rather a variation between individual dogs. They concluded that welfare may be more related to the type of experience the dog has in a kennel setting rather than linked to length of stay. This seems to suggest that kennel enrichment is key to providing good welfare for shelter dogs.

\section{Decreasing Behavioral and Physiological Indicators of Stress in Shelter Dogs}

To help decrease the behavioral and physiological signs of stress in dogs, recent studies have emerged that investigated creative solutions to lower stress in kenneled dogs. Several studies (Biele, 2012; Wells, Graham, \& Hepper 2005, Kogan, Schoenfeld, \& Simon 2012) have investigated the effects of different types of music on stress levels in shelter dogs. In one study heavy metal, classical music, and specifically altered classical music were played and the animal's behaviors were observed (Kogan, Schoenfeld, \& Simon 2012). The altered classical music was marketed for the purpose of calming dogs. The music's 
creator claimed that it had been psychoacoustically designed with the goal of creating music to soothe dogs. The dog's behaviors including vocalization, activity level and body shaking were recorded every five minutes during the 45 minute music session and during the 15 minutes of silence following each session. The study concluded that classical music promoted the most restful behaviors observed, with heavy metal producing the most agitated behaviors while the altered classical music had minimal effects.

In another study researchers used different types of olfactory stimuli, such as lavender, to determine the effect on shelter dogs. (Wells, Graham, \& Hepper 2005). Behaviors were observed and recorded every ten minutes for a four hour period three times a week. Behaviors that were recorded included: vocalizations, movements, sleeping and pacing. The results indicated that lavender and chamomile were associated with behaviors that were considered restful and relaxed. The information suggests that a relationship does exist between traditionally relaxing smells and a lower instance of stressrelated behaviors in dogs. The olfactory and musical studies were well received because of the ease with which these practices could be incorporated at the shelters.

\section{Behavioral and Physiological Responses to Human Interactions in Dogs}

As shelters have looked into different types of enrichment programs for their dogs many volunteers have wanted to help. This increase in volunteer interaction with shelter dogs has led to a new question: Can human contact have an impact on stress-related responses in shelter dogs? To answer this question the human-dog relationship needs to be examined. Dogs have been domesticated for an estimated 11,000-16,000 years (Serpell 1995). Domestication has caused dogs to look to people as their primary caregivers 
(Serpell 1995). The human-dog interaction is in many ways analogous to the parent-child interaction. The parent (dog owner) is responsible for nurturing and protecting the child (dog) (Serpell 1995). The nature of this interaction has led researchers to develop studies that look at the physiological and behavioral responses of the human-dog interaction.

One such study looked at the human-dog interaction from a physiological perspective. The researchers looked at 10 female owners and their 10 male Labradors (Handlin 2012). The relationship between the owners and their dogs was measured using the Monash Dog Owner Relationship Scale (MDORS). The Monash Dog Owner Relationship Scale is comprised of 28 questions based on research concerning the human-dog relationship (Dwyer 2006). They then took blood samples from each dog and owner after 60-minute interaction to measure cortisol and oxytocin levels. Oxytocin is a hormone released from the pituitary gland that acts as a neurotransmitter for the brain (Kemp 2011). Oxytocin is commonly referred to as the "love hormone" as it is closely associated with kissing, hugging, maternal attachment and empathy (Kemp 2011). The researchers found that both the owners and dogs were affected by the interaction session. In the case of the dogs they found a correlation between certain MDORS scores and hormone levels. For example owners who stated they kissed their dogs more frequently had dogs whose oxytocin levels were higher after the interaction. Also the owner's oxytocin levels were significantly correlated with their dog's oxytocin level. This study shows how the relationships people have with their dogs can affect both in a physiological way.

In regards to a behavioral impact that human interaction can have on dogs a team of researchers looked at the differences between dog-dog play and dog-human play (Rooney 
2000). They wanted to see if the types of play were motivationally distinct. To do this they conducted three separate studies: an observation study of dogs being walked by their owners, a survey of dog owners and an experimental play comparison between dog-dog interaction and dog-human interaction. They found that dogs being walked together played with their owner at the same frequency as dogs that were walked alone. The questionnaire also found no difference between the amounts of time dogs spent playing with their owner in a single dog household vs. a multi-dog household. Finally the dogs were much less likely to act possessive of a toy when playing with humans and were more likely to present the toy to a human. These findings suggest that dog are playing with a different type of motivation when interacting with humans vs. other dogs. This means that interaction with a human does cause a behavioral impact on dogs.

Expanding upon the dog-human play research a team of investigators wanted to see if the type of play that a dog and human participate in has an effect on the dog's cortisol levels (Horváth 2008). They used two different groups of working dogs: police dogs and border patrol dogs. The handlers played with the dogs with a tug toy for 3 minutes. The police handlers were mainly disciplining their dogs during the session while the handlers of the border patrol dogs offered more affectionate behaviors. They found that the police dogs' cortisol levels increased significantly while the border patrol dogs' cortisol levels decreased. The study shows that behaviors associated with control and authority increase cortisol levels while affectionate behaviors decrease levels of cortisol during play. Again this study supports evidence that human interactions can affect dogs in a physiological way. 
Another study looked at the behavioral and heart rate responses of 30 dogs when they were approached by a threatening stranger with their owner vs. without their owner (Gácsi 2013). Heart rate (HR) and heart rate variability (HRV) were recorded before, after and during the encounter. When dogs faced the stranger without their owner they exhibited a higher number of vocalizations. There was an increase in HR when the stranger approached whether the owner was present or not; however the HR increase was significantly less pronounced when the owner was present. Also the order in which the test was performed proved to be significant. Dogs that faced the stranger with their owner present first had a smaller HR increase when they faced the stranger alone as compared to dogs that faced the stranger without their owner first. The researchers concluded that owners could provide a buffer against stress and also reduce stress caused by the same threatening stimuli later when the owner was not present.

In regards to the impact of human contact on shelter dogs there was study that looked at the effects of human socialization on pituitary-adrenal hormone levels and behavior (Hennessy 2006). They split the dogs into a socialization group and a control group. Both groups underwent a pre-test that consisted of having blood drawn for hormone analysis, responses to basic commands and observation of behavior in a novel situation. The dogs in the socialization group received training from prison inmates. After three weeks a post-test that was identical to the pre-test was performed. The researchers found that the socialized group displayed less jumping and vocalizing around unfamiliar humans. There was no difference in plasma cortisol levels for the pre and post-test for both groups of dogs. However there was an increase in adrenocorticotropic hormone (ACTH) in both groups over time. Adrenocorticotropic hormone is secreted by the anterior pituitary 
gland in response to biological stress. The investigators concluded that socialization had a positive impact on the dogs' behavior and also supported the theory that shelter housing results in a dysregulation of the hypothalamic-pituitary-adrenal axis (HPA). The HPA is a set of influences and feedback interactions among the pituitary gland, the hypothalamus and the adrenal glands (Tsigos 2002). The HPA axis plays a very important role in controlling reactions to stress (Tsigos 2002). A breakdown of the HPA axis can result in the overproduction of cortisol which further increases the stress response (Tsigos 2002).

The studies presented above provide evidence for familiar humans having an effect on their dogs both physiologically and behaviorally. Does the same thing happen when a dog interacts with a human they are not as familiar with? Researchers in one study used two different groups of kenneled dogs: shelter dogs and dogs in a long-stay enrichment program (LSE) (Pullen 2012). They exposed both groups of dogs to a volunteer that they were either familiar with (F) or unfamiliar with (UF). The person sat in a pen for 10 minutes and only interacted with the dog if they were within arm's reach. They found that the shelter dogs initially spent a longer amount of time near familiar (F) people but after 2 minutes spent a longer amount of time near the volunteer regardless of familiarity. The LSE dogs did not show a significant difference between time spent with F or UF people but on day 3 of the study started spending significantly more time with UF people. They concluded that the shelter dogs considered contact with a person valuable regardless of familiarity. The LSE dogs sought out UF human contact more often perhaps due to the large amount of human interactions they receive on a daily basis. This study shows that contact with a person, in regard to shelter dogs, does have a behavioral effect on the dog regardless of how familiar they are with the person. 
A study conducted in 2009 aimed to see if a human interaction program would have a statistical impact on behaviors observed in shelter dogs (Normando 2009). The dogs were divided into an experimental group that participated in the program and a control group that did not participate but was exposed to human visual stimuli. The dogs in the program were walked from day 8 until day 42. Researchers performed behavioral observations via instantaneous scan sampling every 3 minutes for 3 hours on 11 of the 64 days. The investigators found that dogs in the program spent more of their time at the front of the kennel and showed an increase in the amount of time spent wagging their tail as compared to the control group even after the human interaction program was stopped on day 42. Behaviors such as these could make dogs appear more adoptable. This study was interesting as it showed that the interaction the dogs received with humans via the walking program had an impact on their behavior even after the program was stopped.

Another study tested the effect of human contact on dogs measured cortisol levels in shelter dogs that were provided human contact from volunteers (Coppola et al., 2012). Salivary cortisol was measured on days 2, 3, 4 and 9 for dogs that had human contact and compared with dogs in the control group that did not have contact. The team found that, by day 3, the dogs provided human contact had lower cortisol levels than those who had not been exposed. This study provided additional evidence that contact with a human (familiar or not) could have a physiological impact on dogs.

Expanding upon the research done in the human contact study mentioned above, a group of researchers investigated three different types of human interactions and their effect on cortisol levels and behavioral responses in shelter dogs (Shiverdecker 2013). 
They used dogs that had been at the shelter for less than 40 hours. The experimental group was exposed to three types of human interaction: passive, petting and play. The control dogs were kept in either the general housing area or in a secluded area. The investigators found that all dogs that were exposed to any of the three human interactions had a significant decrease in cortisol levels. The control group had no decrease in cortisol levels. Behavioral dogs in the experimental group exhibited less vocalizations and fear-related panting. All of the studies presented here provide evidence that human contact does have an effect on stress-related responses in shelter dogs.

\section{The Effect of the Human Voice on Horses and Dogs}

If human contact can affect dogs in both a behavioral and physiological way can listening to the human voice have the same impact? There have been only a few studies performed looking at the effect of the human voice on an animal. A recent study was conducted looking at the effect of the tone of the human voice in relation to horse behavior (Merkies et al., 2013). The researchers used eight draft horse geldings. The horses were put in a round pen and videotaped for 10 minutes. The horse's initial behaviors were recorded as was their heartrate. A familiar human approached the round pen and the horses were then exposed to one of the four voice tone recordings for 10 second durations. The recordings included: pleasant low tone, pleasant high tone, stern low tone and stern high tone. They recorded the horse's behavior every second during the voice exposure and then for 10 seconds after the recording was stopped. They found that when the pleasant tone recordings were played the horses oriented their bodies toward the human. The horse's heartrate showed a significant increase with the stern low tone voice. The researchers 
concluded that the horses did respond both behaviorally and physiologically to the different pitches and tones of voice.

Do dogs also exhibit behavioral and physiological responses to the human voice? In order to answer this question it is important to consider how dogs process human vocalizations. An interesting study conducted in 2014 found that dogs process speech, meaning and emotional content in a similar way to humans (Ratcliffe 2014). The study used a head orienting design to test dogs' attention to different vocal stimuli that involved speech or intonation. The researchers found that the dogs turned their heads to the left when there were no words but a positive intonation which indicated right hemispheric $(\mathrm{RH})$ processing. When exposed to familiar commands in their owner's language the dogs turned their head to the right which suggested left hemispheric (LH) processing. In the human brain the intelligible meaning of words is processed in the LH whereas the RH is more sensitive to intonation, stress and rhythm in speech. This emphasizes that dogs do listen to our words and tone of voice. Studies such as this provide support for the use of human vocal stimuli to engage dogs in a kennel environment.

Building upon the research from the preceding study a group of researchers took it one step further by using fMRI technology to compare the voice sensitive regions in the canine brain to the human brain (Andics 2014). They hypothesized that the regions would be similar because dogs and humans have shared a similar social environment for thousands of years. Thus being able to interpret vocalizations between the two species would be important. The investigators presented 11 dogs and 22 humans who were awake inside an MRI machine with the same vocal and nonvocal stimuli. They found that dogs 
possess an area of their brain that interprets human vocal cues and this area is very similar to the voice processing center in humans. They also found that dogs and humans engage a similar nonprimary auditory region of the brain when exposed to different vocal emotional cues. This provided evidence that dogs do understand when we are talking to them and also have a grasp of emotional tone. This type of research helps provide evidence that listening to the human voice could have an effect on dogs.

\section{Conclusion}

Even with studies such as the ones mentioned above research concerning animal stress especially in its relation to shelter animals is very limited at this time. The field is new and wide open to different ideas. The literature reviewed here has shown that stress does have an impact on shelter dog's behavioral and physiological responses. These responses can result in dogs being adopted at a lower rate. There are many different kinds of enrichment programs that have been developed with the hopes of decreasing these stress-related responses. Programs that involve human contact (i.e. walking, playing and training) are becoming more popular and have been shown to have a positive impact on dogs behaviorally and physiologically. While there has been recent research regarding dog's responses to the human voice these studies have focused on how dogs process human vocalizations. The effect of the human voice on canine stress-related behavior has not been sufficiently explored. The intent of this study is to expand upon the current literature in this field. As shelters continue to explore methodologies to reduce stress in a cost effective way for the animals in their care, investigations into this field will be highly valued. Determination that audiobook recordings can be used to lower stress-related 
responses in shelter dogs can potentially provide an additional low cost tool for shelters to utilize. 


\section{Chapter 3}

\section{Methods}

\section{Housing and Dogs}

Twenty dogs housed at the Kanawha -Charleston Humane Association Animal Shelter during the period of July 7, 2014 to August 2, 2014 were recruited for inclusion in the study. The number of dogs was chosen after a consultation with a statistician as this number provided statistically significant results. Dogs were excluded if they were under 6 months of age or had been at the shelter for less than three days. All included dogs were housed in identical cages with only a water bucket and bed. The kennels were set up so that ten dogs were in the first section and ten dogs were in a separate section. The experimental and control group each consisted of 10 dogs. The study used a randomized block design where both groups (experimental and control) consisted of the same gender ratio (3 males:2 females) and same average age (3 years). Both groups were exposed to all treatment types. This design was a modified version of the experimental design utilized by Kogan, Schoenfeld and Simon in their musical study (Kogan, Schoenfeld \& Simon 2012). The design had to be modified because the dogs were not all housed in one kennel section but in separate sections. The sections were separated by a noise reducing metal door.

\section{Behavioral Ethogram}

The behavioral chart designed for this study was based on previously published research on canine body language as well as preliminary observations of kennel behaviors 
exhibited by dogs (Protopopova et al., 2014). Table 1 outlines the full list of behaviors and their respected definitions. It consists of 13 stress-related and 5 nonstress-related behaviors giving a total of 18 behaviors (Table 1). The behaviors that were categorized as stress-related included the following: growling, barking, whining, turning away, pinned ears, lowered head, leaning backwards, pinned tail, lip licking, yawning, pacing, panting and shaking off. Behaviors that were categorized as nonstress-related included the following: sleeping, sitting, tail wagging, standing relaxed and lying down.

Table 1. Ethogram of Behaviors of Kenneled Shelter Dogs. This table provides the definitions used by researchers to identify different markers of stress-related and nonstress-related behavior exhibited by dogs in kennels.

\title{
Ethogram of Behaviors of Kenneled Shelter Dogs
}

\author{
Behaviors Definitions for Study \\ Vocalizations \\ Growling a low vocalization from the throat \\ Barking a vocalization of low frequency and short duration \\ Whining long high pitched vocalization \\ Stress-related Movements \\ Turning Away physically turning body away from stimulus \\ Pinned Ears ears being held extremely close to the head \\ Lowered Head head moving close to the floor with tension \\ Leaning backwards moving body back from stimulus \\ Pinned Tail tail being carried extremely close to the body with tension \\ Lip Licking licking the face excessively (more than three times consecutively during observation) \\ Yawning yawning more than 2 times consecutively during observation \\ Pacing moving back and forth in the kennel is a repetitive motion \\ Panting breathing with tongue out when temperature is not hot and no exercise has been given \\ Shaking Off shaking the body repeatedly during observation \\ Nonstress-related Movements \\ Sleeping dog is lying down sleeping \\ Sitting hind-end is on the floor \\ Tail Wagging tail is moving back and forth in relaxed manner \\ Standing Relaxed standing with four paws on the ground, tail lowered \\ Lying Down body is on the ground in a reclined position
}




\section{Subgroups of Behaviors}

The behaviors outlined in the ethogram were divided into two groups: vocalizations, and movements. The movements were categorized as either stress-related or nonstressrelated. All of the vocalizations were considered stress-related behaviors. The subgroups (vocalizations and movement type) were created to allow for further statistical analysis.

\section{Voice Variables}

The study used three different audiobook narrators to provide a varied amount of accents and vocal tones (Dickens 2008; Poehler 2014; Stevenson 2006). One narrator was a male with a British accent, the second was a man with a Midwestern accent and the third was a woman with a Midwestern accent. Each of the recordings consisted of the narrator speaking and no other sound effects.

\section{Data Collection}

A RCA stereo was placed inside the front section of the kennel area for the experimental group. The stereo played one of the recorded audiobook selections for a period of forty-five minutes. This time period was chosen based on previous models of research pertaining to stress in shelter dogs (Kogan, Schoenfeld \& Simon 2012; Wells, Graham, \& Hepper 2005) and it also allowed the flow of shelter visitors to not become disrupted. Each session took place at 11:00 a.m. as this was the time of day when shelter workers had finished cleaning the kennels and the shelter was not yet open to the public. During this period the same three observers recorded behavioral observations every five minutes for a total of nine observations per dog per session (Figure 1). The observers 
consisted of: one kennel worker, one dog trainer and one animal physiology graduate student. If the dog was showing both a stress-related and nonstress-related behaviors simultaneously then the stress-related behavior was recorded. Each observer performed an independent assessment of each dog's behavior. The behavior recorded was based on a consensus reached between the observers. The observers used digital video cameras to view the dogs without disturbing them. There were 12 cameras that were positioned so that each kennel was clearly visible to the observers. The observers were aware of the treatment status for dogs during the behavioral recording sessions.

For four weeks the dogs were exposed to each of the three audiobooks for forty-five minute sessions. The sessions occurred every Monday, Thursday and Saturday. This gave a total of 12 sessions recorded. For the purpose of statistical analysis the data was averaged for each dog for each behavior type (stress-related or nonstress-related) and for each subgroup behavior type (vocalizations or movement type) (total number of observations for behavior type or subgroup type of interest for dog/12 sessions). The study used a crossover AB/BA design where every week the experimental group of dogs was switched with the control group (Figure 2). This allowed the study to have more observational subjects and thus more statistical power.

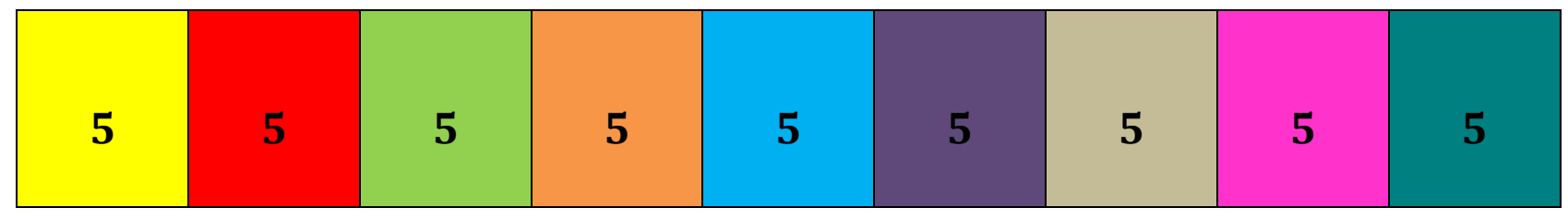

Figure 1: Behavioral Observation Collection Method. The experimental group was exposed to the audiobook for 45 minutes. Behaviors were recorded every 5 minutes for a total of 9 behaviors per dog for each session. The 9 blocks represent each 5 minute time block. The behavior the dog was expressing at the five minute mark was the behavior recorded. There could be only one behavior recorded for each time block. 


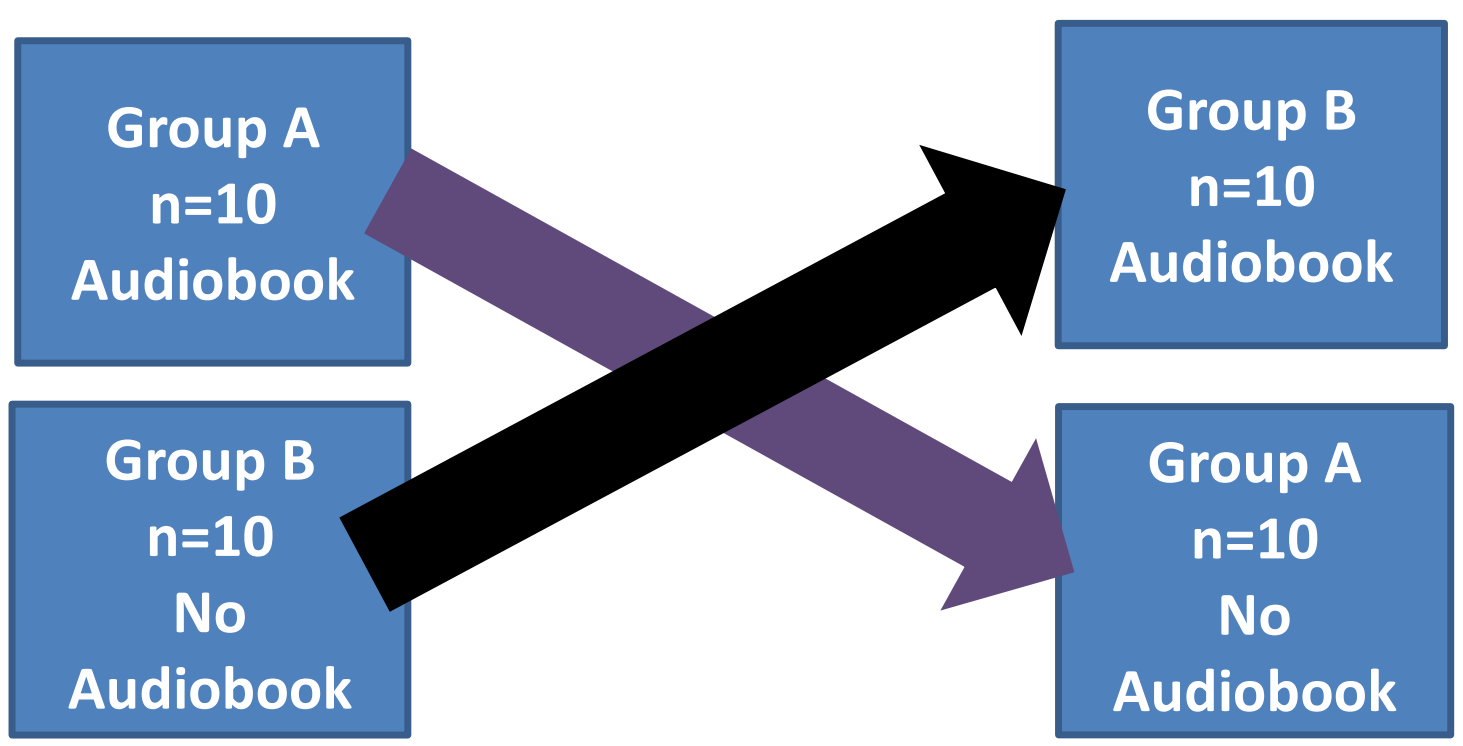

Figure 2: Cross-over Design. The dogs in Group A were exposed to the audiobook first then were switched with Group B to be in the no audiobook group. The dogs in Group B were initially in the no audiobook group then they were switched with Group A to be in the audiobook group. The switch occurred three times during the study to give each group 6 sessions in the audiobook group and 6 sessions in the no audiobook group.

\section{Statistical Analysis}

Data were analyzed using JMP software (JMP®, Version Pro 11, SAS Institute Inc., Cary, NC, Copyright (C2013).The variables were checked for normality using Shapiro-Wilk W test and were shown to be normally distributed except in two cases: the amount of vocalizations by treatment type and the stress-related movements by the three different voice variables. These subsets of data were analyzed using two nonparametric methods called the Wilcoxon signed rank test for two groups and Kruskal-Wallis Test for three groups. Since we used the cross-over experimental design and all of the dogs were interchangeably exposed to both audio and control treatment, all of the normally distributed average counts of behaviors were analyzed using the matched pairs t-test analysis across groups. This analysis was applied to compare the average number of behaviors between the audio and control treatment groups for both stress-related and 
nonstress-related behaviors as well as to compare the response among the three accent groups (female, male British and male Midwestern) within the audio-treated group only. In addition, matched pairs analysis for groups was used to analyze the mean behavioral responses on each sampling day using the whole room of dogs as an experimental unit. The statistical significance for all the tests was $\mathrm{P}=0.05$. 


\section{Chapter 4}

\section{Results}

\section{Subjects}

The dogs that participated in this study were between 1-8 years old with an average age of 3 years. There were 12 males and 8 female dogs that participated with 6 males and 4 females in each group. The dogs were composed of a mixture of purebreds and mixed breeds. The shelter identified 4 dogs as purebreds and 16 dogs as mixed breeds. There were 2 dogs that were neutered and 18 that were unneutered. The dogs had been at the shelter for an average of five days at the start of the study.

\section{Behaviors Observed}

Each dog had 108 recorded behavioral observations ( 9 observations/session x 12 sessions) over the course of the four week study, which gave a total of 2,160 behavioral observations (108 observations/dog x 20 dogs). Figures 3-4 graphically displays the recorded behavioral observations. The behaviors that were categorized as stress-related were recorded at higher amounts for dogs in the control group (Figure 3). Barking vocalizations were two times greater for the control group as compared to the audio group while pacing was twelve times greater in the control group (Figure 3). Behaviors that were categorized as nonstress-related were recorded at higher amounts for dogs exposed to the audio recordings (Figure 4). Lying down behavior was six times greater in the dogs exposed to the audio recording, sitting was three times greater for the audio group and 
sleeping was eighteen times greater for the audio group dogs (Figure 4). Figure 5 depicts nonstress-related behaviors versus stress-related behaviors. Stress-related behaviors were observed 3 fold more often for the control group whereas nonstress-related behaviors where observed 3 fold more often in the audio group (Figure 5).

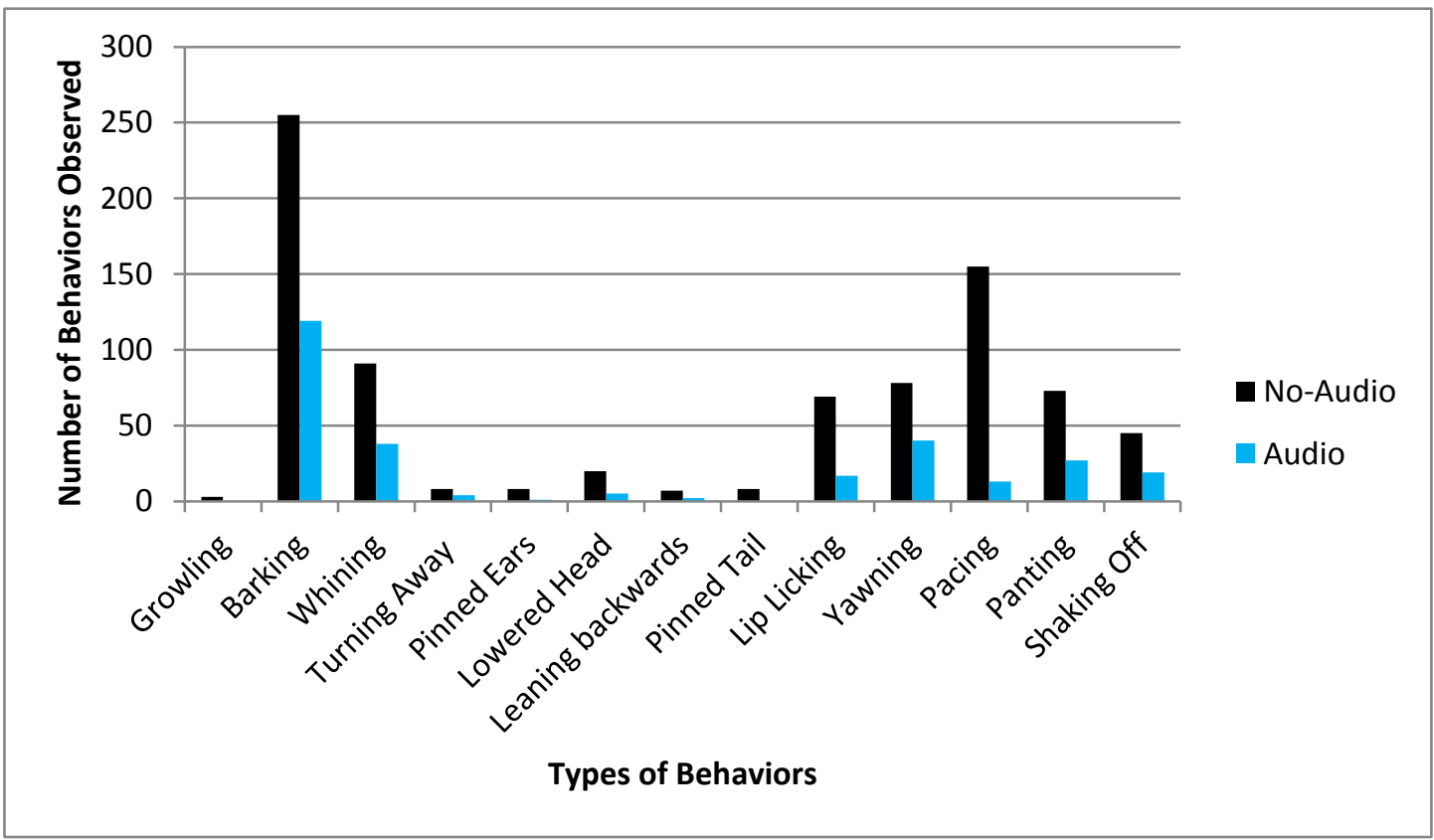

Figure 3. Stress-related Behaviors Observed When Exposed to Auditory Stimulus. The graph displays the number of each listed behavior observed in the dogs $(\mathrm{N}=20)$ when exposed to the audiobook recording or exposed to no auditory stimulus (control). 


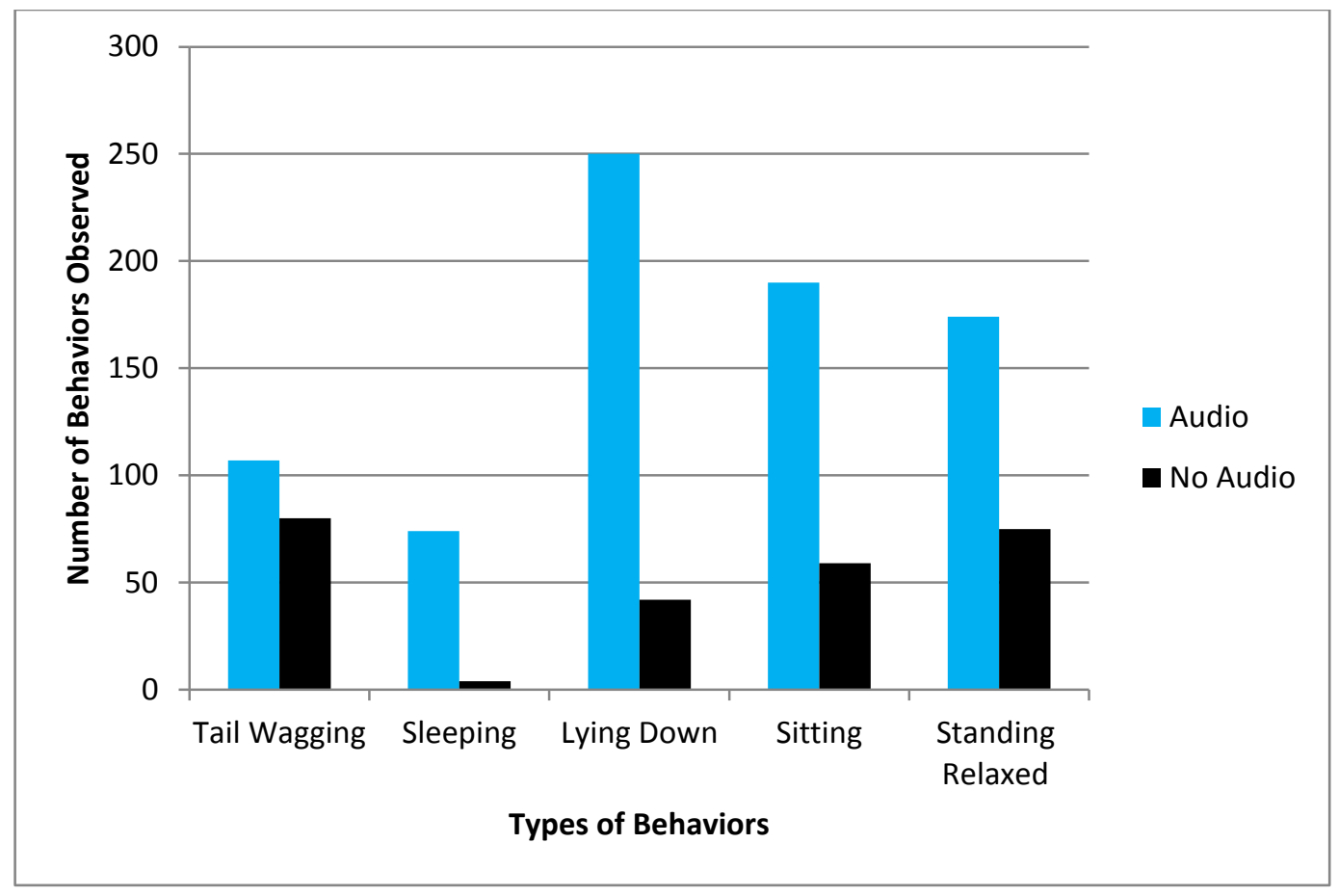

Figure 4. Nonstress-related Behaviors Observed When Exposed to Auditory Stimulus. The graph displays the number of each listed behavior observed in the dogs $(\mathrm{N}=20)$ when exposed to the audiobook recording or exposed to no auditory stimulus (control).

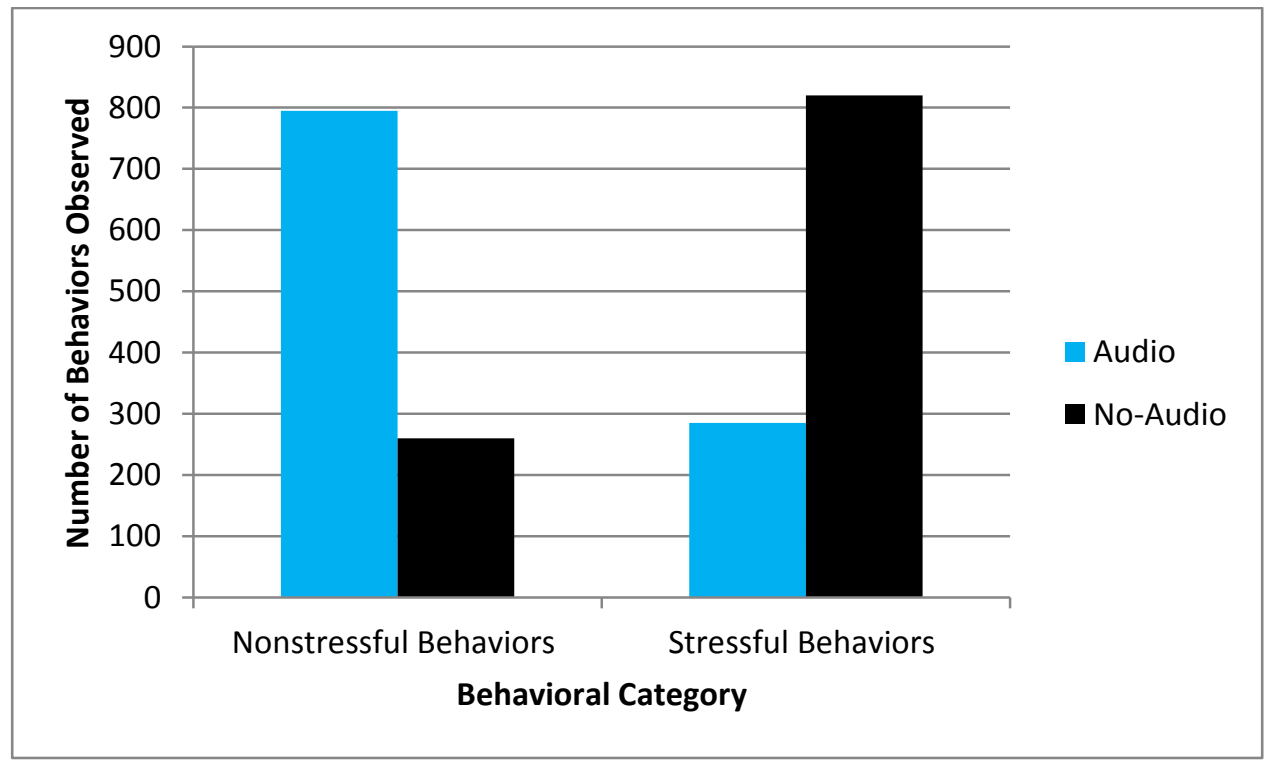

\section{Figure 5. Types of Behaviors Observed in Dogs for Audio vs. Non-Audio}

Stimulus. The figure displays the total number of nonstress-related behaviors (i.e. sitting, relaxed standing, sleeping, tail wagging, lying down) and stressrelated behaviors (i.e. pacing, barking, lip licking, pinned ears etc.) observed in dogs $(\mathrm{N}=20)$ when exposed to an audiobook recording or no audio recording. 
Table 2. Descriptive Statistics of Observed Behaviors. The table shows the percentage of time each subgroup of behavior was observed during the audiobook exposure, the audio variations and the control (no audiobook) exposure for $\mathrm{N}=20 \mathrm{dogs}$ with an $\mathrm{AB} / \mathrm{BA}$ crossover design.

$\begin{array}{llllll} & & \text { Voice Variables } & \text { Total Audio } & \text { Total Control } \\ & \text { British } & \text { Female } & \begin{array}{l}\text { Midwestern } \\ \text { Male }\end{array} & & \\ \text { Vocalizations } & 58(16.1 \%) & 62(17.2 \%) & 62(17.2 \%) & 182(16.9 \%) & 349(32.3 \%) \\ \text { Stress-related Movements } & 46(12.8 \%) & 43(11.9 \%) & 44(12.2 \%) & 133(12.3 \%) & 471(43.6 \%) \\ \text { Non-Stressful Movements } & 257(71.4 \%) & 256(71.1 \%) & 252(70.0 \%) & 765(70.8 \%) & 260(24.1 \%) \\ \text { Total Observations } & 360 & 360 & 360 & 1080 & 1080\end{array}$

\section{Behavioral Descriptive Summary}

The information presented in Table 2 shows the number of times each subgroup behavior was exhibited and percentages of the behaviors observed during the forty-five minute observation period. The observations were recorded every five minutes for each dog. Dogs that were exposed to the audiobook recordings expressed behaviors that were considered nonstress-related including lying down, sitting and sleeping $70.8 \%$ of the time as compared to the control group which expressed these behaviors $24.1 \%$ of the time. The dogs that were exposed to no auditory stimulus displayed stress-related movements 43.6 $\%$ of the time as compared with the audio group that expressed these behaviors $12.3 \%$ of the time. Dogs that heard the audiobook exhibited vocalizations $16.9 \%$ of the time as compared to the control group which vocalized $32.3 \%$ of the time.

\section{Nonstress-related Behaviors vs. Stress-Related Behaviors}

A matched t-test was performed on the averages of each dog's behavioral responses over the twelve sessions. Each value was sampled independently giving 20 behavioral responses for both stress-related and non-stress related behaviors. The t-test yielded a 
large $\mathrm{f}$ ratio $(\mathrm{F}=662.5)$ and a $\mathrm{p}$ value $(\mathrm{P}<.0001)$ that is smaller than $\mathrm{P}=0.05$. This indicated that there was a significant difference between the number of nonstress-related and stress related behaviors recorded for the dogs when they were exposed to the audiobook stimulus vs. no auditory stimulus $(\mathrm{P}=0.05)$ (Table 3$)$. The mean difference was opposite for the nonstress-related and stress-related behaviors which shows that the values for these groups went in different directions. Figure 6 illustrates how stress-related behaviors were recorded at a much higher rate for the no audio group and nonstress-related behaviors were much more prevalent for the audio group. This supports the hypothesis that the treatment type (no audio vs. audio) would have a significant impact on the type of behaviors observed (nonstress-related vs. stress-related) $(\mathrm{P}=0.05)$ (Figure 6).

Table 3. Matched t-test to Compare Total Number of Nonstress-related and Stress-related Behaviors in the Audio vs. Control Groups. The table displays the results of the matched t-test. The results were considered significant at $\mathrm{P}=0.05$. The mean difference is shown as significant for within the pairs of data. The mean mean value is not significant due to the cross-over design of the study.

\begin{tabular}{|c|c|c|c|c|}
\hline \multicolumn{5}{|c|}{ Difference: NoAudio-Audio } \\
\hline Behavior Type & Count & Me & Difference & Mean Mean \\
\hline Nonstress-related & 20 & & -4.134 & 4.3165 \\
\hline Stress-related & 20 & & 4.134 & 4.6835 \\
\hline Test Across Groups & & tio & Prob $>F$ & \\
\hline Mean Difference & 662 & & $<.0001^{\star}$ Within Pairs & Y Axis \\
\hline Mean Mean & & 864 & 0.1475 Among Pairs & $X$ Axis \\
\hline
\end{tabular}




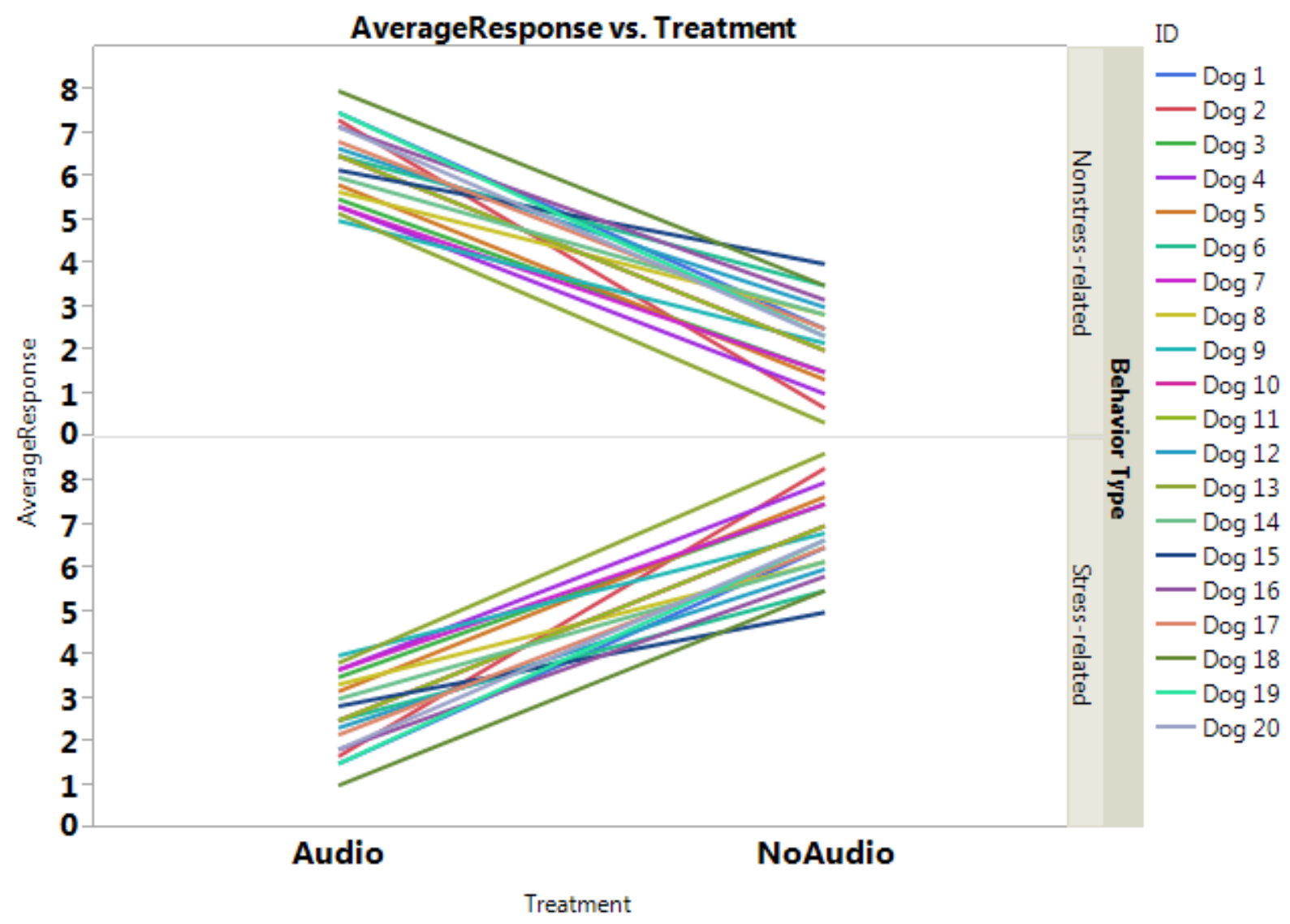

Figure 6. Matched Pairs Difference for Nonstress-related and Stress-related Behaviors for Audio vs. Non-Audio. The figure displays the average number of behavior types (stress-related vs. nonstress-related) for each treatment types (audio vs. no audio) for each dog for all 12 sessions. The dogs are all color coded and their responses are matched for each behavior types. The figure shows that when exposed to the audiobook each dog displayed fewer stress-related responses and more nonstress-related responses and vice versa.

\section{Difference in Amount of Vocalizations by Treatment Type}

The difference in the number of vocalizations observed between the audio and control group was analyzed via nonparametric Wilcoxon signed rank test and KruskalWallis test because the data were not normally distributed. The p value $(\mathrm{P}<.0001)$ in Table 4 indicate that there was a significant difference between the amount of time the dogs 
spent vocalizing (i.e. barking, growling and whining) in the audio vs. no audio group

$(\mathrm{P}=0.05)$. The $\mathrm{p}$ value $(\mathrm{P}<.0001)$ supports this as it also shows a significant difference in the two groups $(\mathrm{P}=0.05)$. Figure 7 illustrates that dogs exhibited fewer vocalizations when exposed to the audiobook recordings as compared to no audiobook recording.

Table 4. Wilcoxon Signed Rank test for Differences in Vocalizations for Audio vs. Control Groups. This table shows the difference between the amount of vocalizations for the audio vs. the no audio group. The small $\mathrm{p}$ value $(\mathrm{P}<.0001)$ indicates that there is a significant difference between the two groups.

\section{Wilcoxon Signed Rank}

$\begin{array}{lr} & \begin{array}{r}\text { NoAudio- } \\ \text { Audio }\end{array} \\ \text { Test Statistic S } & 105.000 \\ \text { Prob }>|S| & <.0001^{*} \\ \text { Prob }>S & <.0001^{*} \\ \text { Prob }<S & 1.0000\end{array}$

Table 5. Wilcoxon/ Kruskal-Wallis Test for Differences in Vocalizations for Audio vs. Control Groups. This table shows the difference between the amount of vocalizations for the audio vs. the no audio group. The chi square value $(\mathrm{H}=22.17)$ and $\mathrm{p}$ value $(\mathrm{P}<.0001)$ indicates that there is a significant difference between the two groups.

\begin{tabular}{lrrrrr}
\multicolumn{2}{l}{$\begin{array}{l}\text { Wilcoxon / Kruskal-Wallis Tests (Rank Sums) } \\
\text { Level }\end{array}$} & $\begin{array}{r}\text { Count } \\
\text { Score Sum }\end{array}$ & $\begin{array}{r}\text { Expected } \\
\text { Score }\end{array}$ & Score Mean & (Mean-Mean0)/Std0 \\
Audio & 20 & 236.500 & 410.000 & 11.8250 & -4.695 \\
NoAudio & 20 & 583.500 & 410.000 & 29.1750 & 4.695
\end{tabular}

\section{1-way Test, ChiSquare Approximation ChiSquare

$1<.0001^{*}$




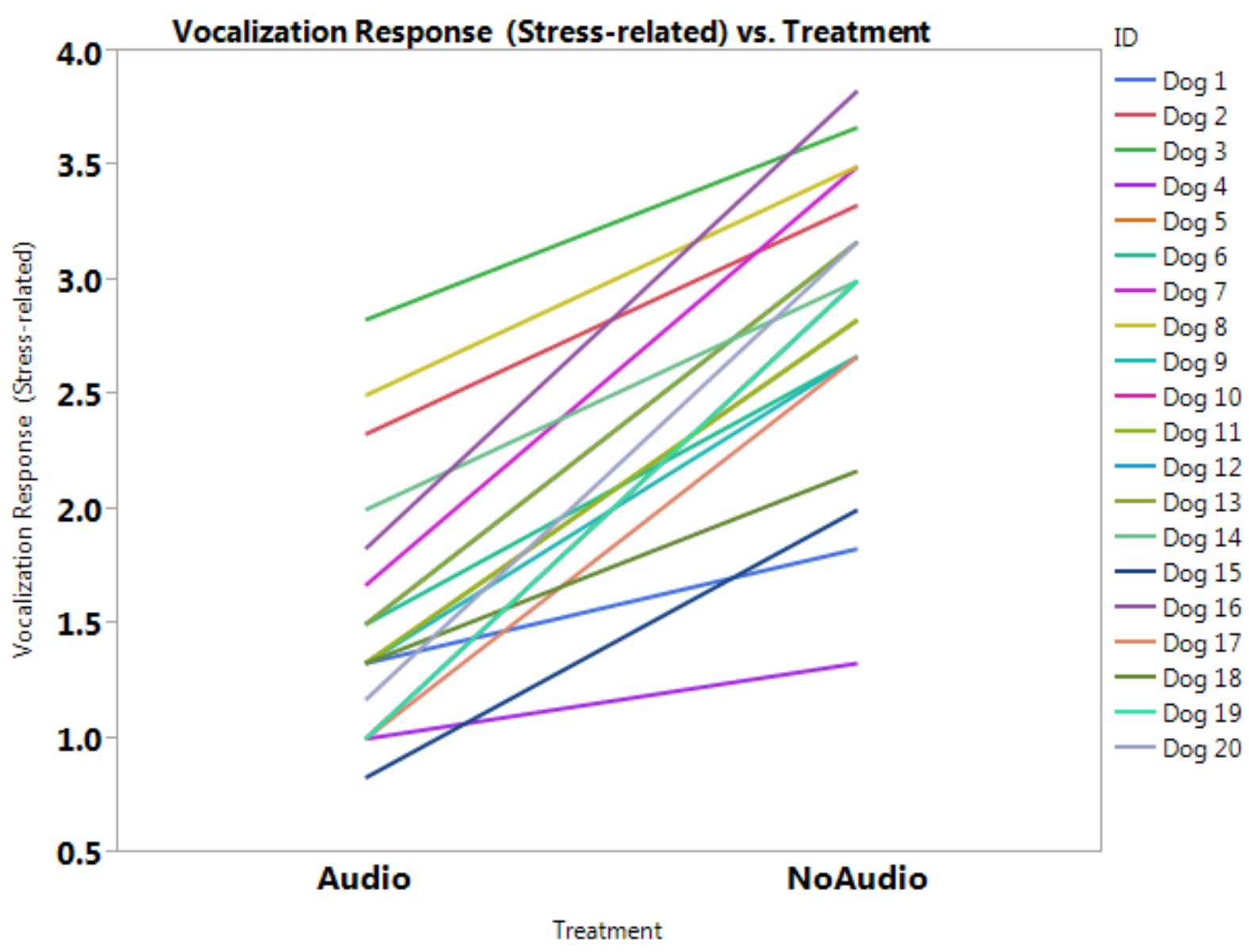

Figure 7. The Average Number of Vocalization Responses by Treatment Type. The figure illustrates the average number of vocalizations for each dog for all 12 sessions. The dogs are all color coded. The figure shows that each dog exhibited an increase in the number of vocalizations recorded when they were exposed to no audiobook vs. when they were exposed to an audiobook.

\section{Difference in Vocalizations by Voice Variables}

A matched t-test was performed on each of the averages for every dog's vocalization responses over the twelve sessions for the different voice variables. Each value was sampled independently giving 60 vocalization responses for each of the three voice variable: male Midwestern, male British and female Midwestern. The results listed in Table 6 show that for each voice variable the $\mathrm{p}$ values $(\mathrm{P}=0.6623, \mathrm{P}=1.0, \mathrm{P}=0.6877)$ were larger 
than $\mathrm{P}=0.05$. This means that there were no significant differences between the number of vocalizations recorded for the different voice variables. Figure 8 illustrates that there were no significant difference found between the three different groups as the graph has no cohesive direction $(\mathrm{P}=0.05)$.

Table 6. Matched T-test for Vocalizations by Voice Variables. The three different sub-tables show the differences in number of vocalizations between the three different voice variables. The highlighted numbers show the $\mathrm{p}$ values for each comparison. All of the $\mathrm{p}$ values were greater than $\mathrm{P}=0.05$ so there were no significant difference between the groups.

\begin{tabular}{|c|c|c|c|}
\hline Male Midwestern & 1.55 & t-Ratio & 0.443724 \\
\hline Male British & 1.45 & DF & 19 \\
\hline Mean Difference & 0.1 & Prob $>|t|$ & 0.6623 \\
\hline Std Error & 0.22537 & Prob $>\mathrm{t}$ & 0.3311 \\
\hline Upper 95\% & 0.57169 & Prob $<\mathrm{t}$ & 0.6689 \\
\hline Lower 95\% & -0.3717 & & \\
\hline $\mathrm{N}$ & 20 & & \\
\hline Correlation & 0.19315 & & \\
\hline Male Midwestern & 1.55 & t-Ratio & 0 \\
\hline Female & 1.55 & DF & 19 \\
\hline Mean Difference & 0 & Prob $>|t|$ & 1.0000 \\
\hline Std Error & 0.23786 & Prob $>t$ & 0.5000 \\
\hline Upper 95\% & 0.49785 & Prob $<\mathrm{t}$ & 0.5000 \\
\hline Lower 95\% & -0.4979 & & \\
\hline $\mathrm{N}$ & 20 & & \\
\hline Correlation & 0.21565 & & \\
\hline Male British & 1.45 & t-Ratio & -0.40825 \\
\hline Female & 1.55 & DF & 19 \\
\hline Mean Difference & -0.1 & Prob $>|t|$ & 0.6877 \\
\hline Std Error & 0.24495 & Prob > t & 0.6562 \\
\hline Upper 95\% & 0.41268 & Prob $<\mathrm{t}$ & 0.3438 \\
\hline Lower 95\% & -0.6127 & & \\
\hline $\mathrm{N}$ & 20 & & \\
\hline Correlation & 0.10335 & & \\
\hline
\end{tabular}




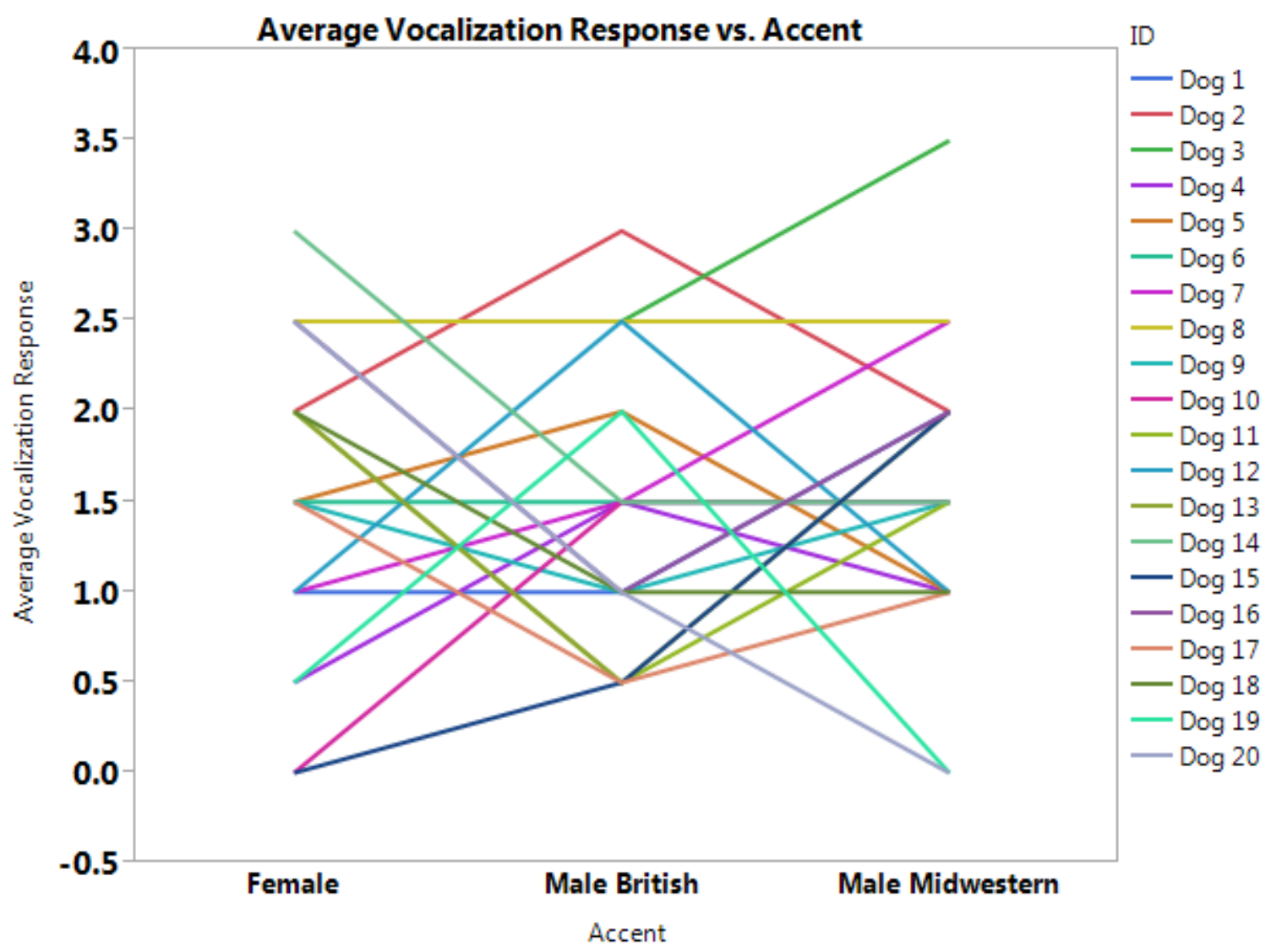

Figure 8. Average Vocalization Response in Audio Group by Voice Variables. This figure illustrates the average number of vocalizations for each of the three voice variables for each dog for all 12 sessions. The dogs are all color coded. The figure shows that there is no difference in the amount of vocalizations recorded for the different voice variables.

\section{Difference in Movement Types by Treatment}

A matched t-test was performed on the averages of each dog's movement type response (nonstress-related vs. stress related) over the twelve sessions. Each value was sampled independently giving 20 behavioral responses for both stress-related and nonstress related movements. The t-test yielded mean difference of -5.32 for the audio group and 1.75 for the no audio group (Table 7). These values resulted in a large $f$ value ( $F=166.5)$ and a small $p$ value $(\mathrm{P}=0.05)$ (Table 7$)$. This indicated that there was a significant difference between the number of stress-related and nonstress-related movements observed for each 
treatment type $(\mathrm{P}=0.05)$. Figure 9 illustrates that the dogs displayed significantly fewer stress-related body movements during the audiobook sessions while displaying significantly higher stress-related body movements during the control period $(\mathrm{P}=0.05)$.

Figure 10 shows that on average dogs in the audio group exhibited nonstress-related movements 5.8 times more often than stress-related movements. On average dogs in the no audio group displayed stress-related behaviors 1.8 times more often than nonstressrelated behaviors (Figure 10).

\section{Table 7. Matched t-test to Compare Total Number of Stress-related Movements in}

Audio vs. Control Groups. The table displays the results of the matched t-test. The results were considered significant at $\mathrm{P}=0.05$. The large $\mathrm{F}$ ratio $(\mathrm{F}=166.5)$ and the $\mathrm{p}$ value that was smaller than $\mathrm{P}=0.05$ indicate a significant difference between the amount of stress-related and nonstress-related movements observed in the different treatment groups $(\mathrm{P}=0.05)$.

\section{Difference: Stress-related movements-Nonstress-related movements}

Stress-related movements

Nonstress-related movements

Mean Difference

Std Error

Upper 95\%

Lower 95\%

$\mathrm{N}$

Correlation
2.5165

4.30025

$-1.7838$

0.62701

$-0.5155$

$-3.052$

40

$-0.9388$
t-Ratio

DF

Prob $>|t|$

Prob $>t$

Prob $<\mathrm{t}$
$-2.84486$ 39

0.0070 *

0.9965

0.0035 *
Test Across Groups

Mean Difference

Mean Mean

$\begin{array}{lrrr}\begin{array}{l}\text { Across Groups } \\ \text { Treatment }\end{array} & \text { Count } & \begin{array}{r}\text { Mean } \\ \text { Difference }\end{array} & \text { Mean Mean } \\ \text { Audio } & 20 & -5.317 & 3.7585 \\ \text { NoAudio } & 20 & 1.7495 & 3.0583\end{array}$

Mean Mean

3.7585

3.0583 


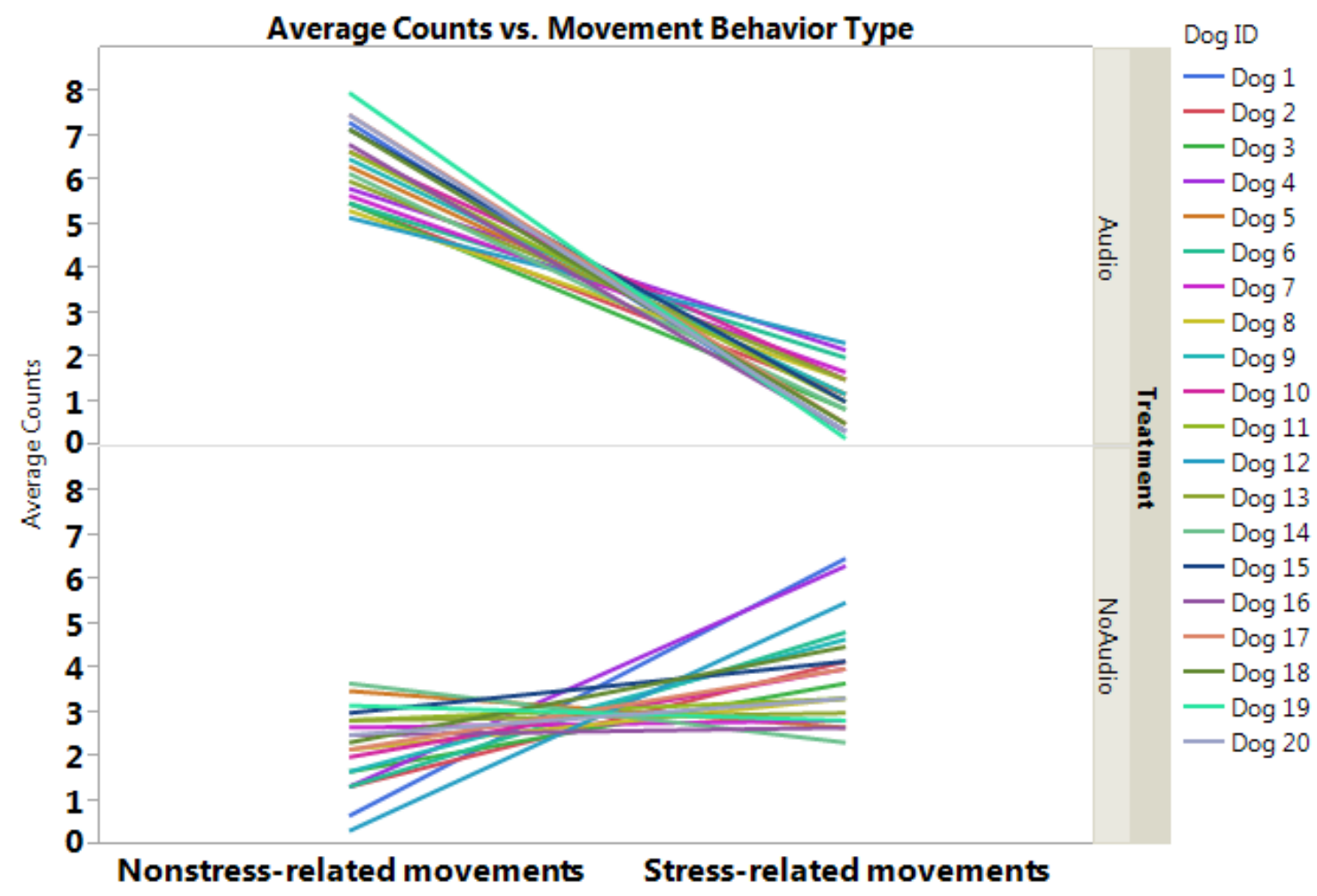

Movement Behavior Type

Figure 9. Average Number of Movement Types by Treatment. This figure illustrates the average number of movement types (stress-related vs. nonstressrelated) for each treatment (audio vs. no audio) for each dog for all 12 sessions. The dogs are all color coded. It shows that dogs in the audio group exhibited a higher amount of nonstress-related movements and dogs in the no audio group displayed a higher amount of stress-related movements. 


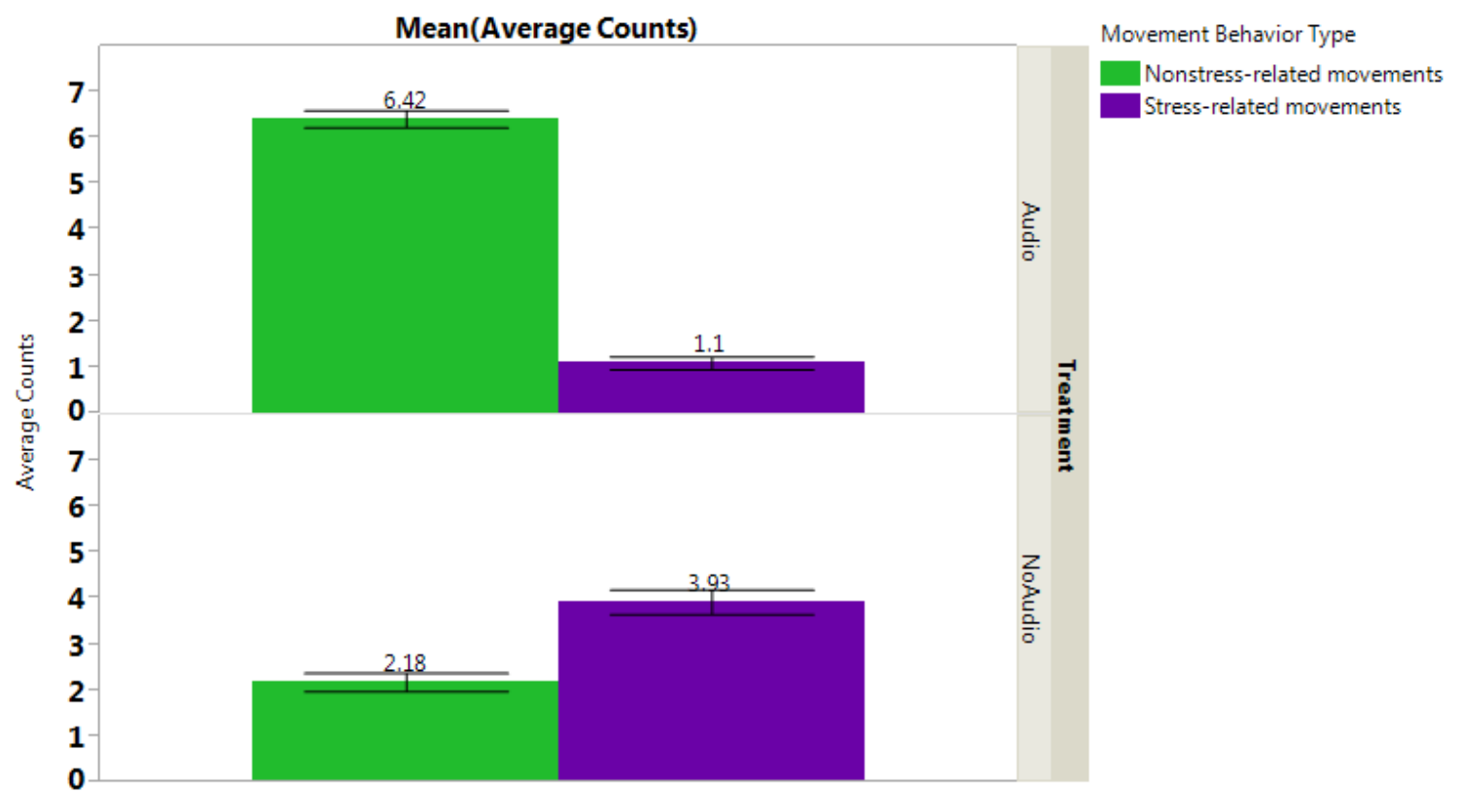

Figure 10. Average Number of Movement Types by Treatment in Bar Graph

Form. This figure illustrates the average number of movement types (stress-related vs. nonstress-related) for each treatment (audio vs. no audio). It shows that dogs in the audio group exhibited on average a higher number of nonstress-related movements and dogs in the no audio group displayed a higher amount of stressrelated movements.

\section{Difference in Movement Type by Voice Variable}

The difference in the number of the two movement types (stress-related vs. nonstress-related) observed between the three different voice variables was analyzed via a nonparametric Wilcoxon signed rank test because the data was not normally distributed. The male-British nonstress-related movements were left skewed and the female and maleBritish stress-related movements were right skewed. Table 8 shows that the mean difference has a $p$ value $(\mathrm{P}=0.9645)$ larger than $\mathrm{P}=0.05$ which signifies that there were no significant differences between the type of movement for each of the three voice variables. Figure 11 illustrates that even though there are no significant difference between the three 
voice variables all three groups showed a decrease in the amount of stress-related movements observed. Figure 12 shows the means for each of the movement types observed for each of the three different voice variables. The averages for nonstress-related movements were: 6.3 for females, 6.43 for male British and 6.3 for male Midwestern. The averages for stress-related movements were: 1.08 for females, 1.08 for male British and 1.1 for male Midwestern. This supports the evidence that there was no significant difference between the voice variables but there was an overall difference between the number of stress-related and nonstress-related movements observed.

Table 8. Wilcoxon Signed Ranked Test for Movement Type by Voice Variable. The table shows the differences between the type of movement observed (nonstress-related vs. stress-related) and the type of voice variable used. The mean difference and mean mean $p$ values are both larger than $P=0.05$. This shows that there were no significant differences between movement types and voice variables.

$\begin{array}{lrrr}\begin{array}{l}\text { Across Groups } \\ \text { Voice Accent }\end{array} & \text { Count } & \begin{array}{r}\text { Mean } \\ \text { Difference }\end{array} & \text { Mean Mean } \\ \text { Female } & 20 & -5.225 & 3.6875 \\ \text { Male British } & 20 & -5.35 & 3.75 \\ \text { Male Midwestern } & 20 & -5.2 & 3.7\end{array}$

Test Across Groups

Mean Difference

Mean Mean

$\begin{array}{rrr}\text { F Ratio } & \text { Prob }>\mathbf{F} & \\ 0.0362 & 0.9645 \text { Within Pairs } & \text { Y Axis } \\ 0.0633 & 0.9387 \text { Among Pairs } & \text { X Axis }\end{array}$

\section{Wilcoxon Signed Rank}

stress-related movements-nonstressrelated movements

Test Statistic S

Prob $>|S|$

Prob $>$ S

Prob $<$ S
$-915.00$

$<.0001^{*}$

1.0000

$<.0001^{*}$ 


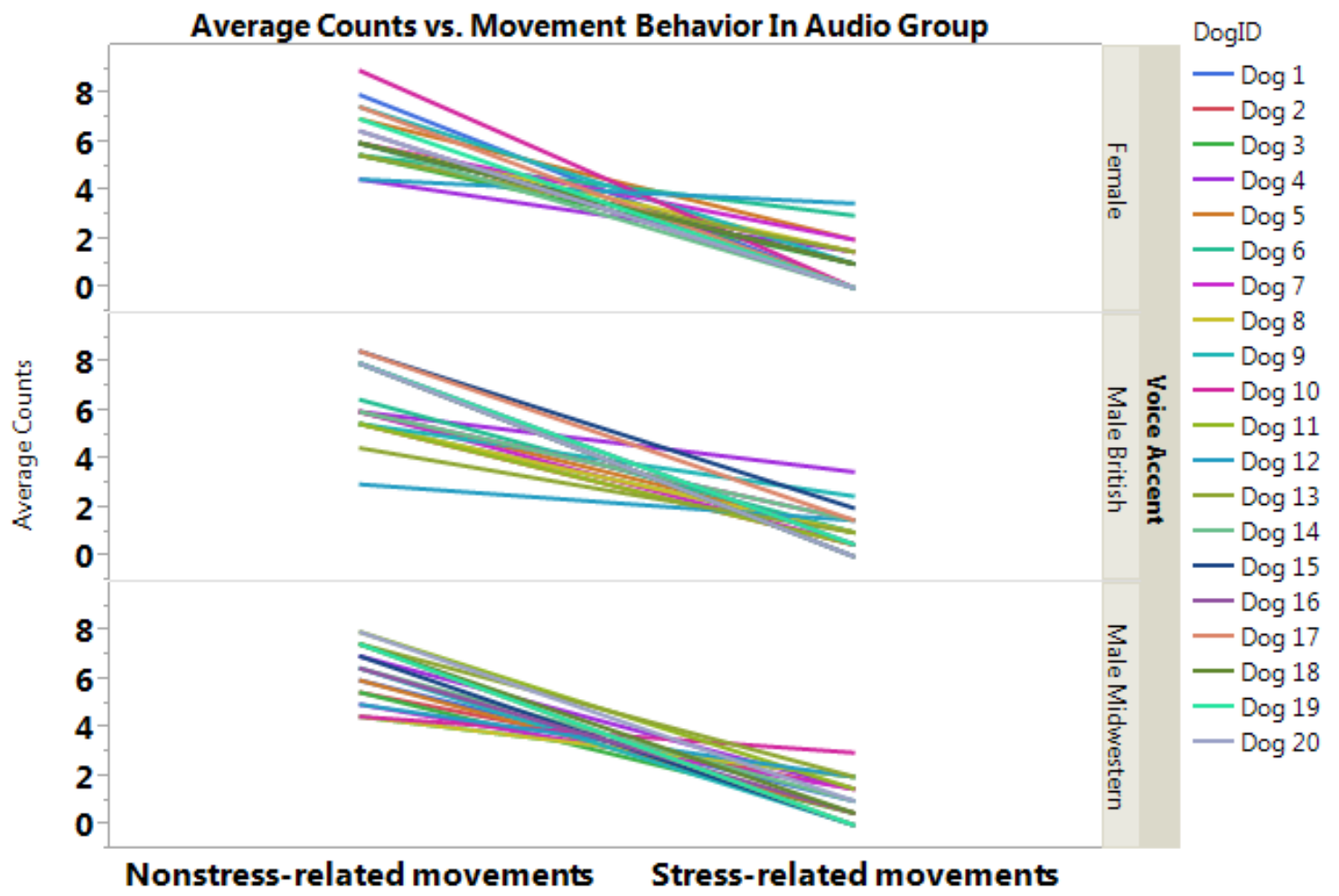

Movement Behavior In Audio Group

Figure 11. Average Number of Movement Types in Audio Group by Voice Variable. This figure illustrates the average number of movement types (stress-related vs. nonstressrelated) for each voice variable for each dog for all 12 sessions. The dogs are all color coded. It shows that each dog showed an overall decline in stress-related movements and a subsequent increase in nonstress-related movements regardless of which voice variable they were exposed to. 


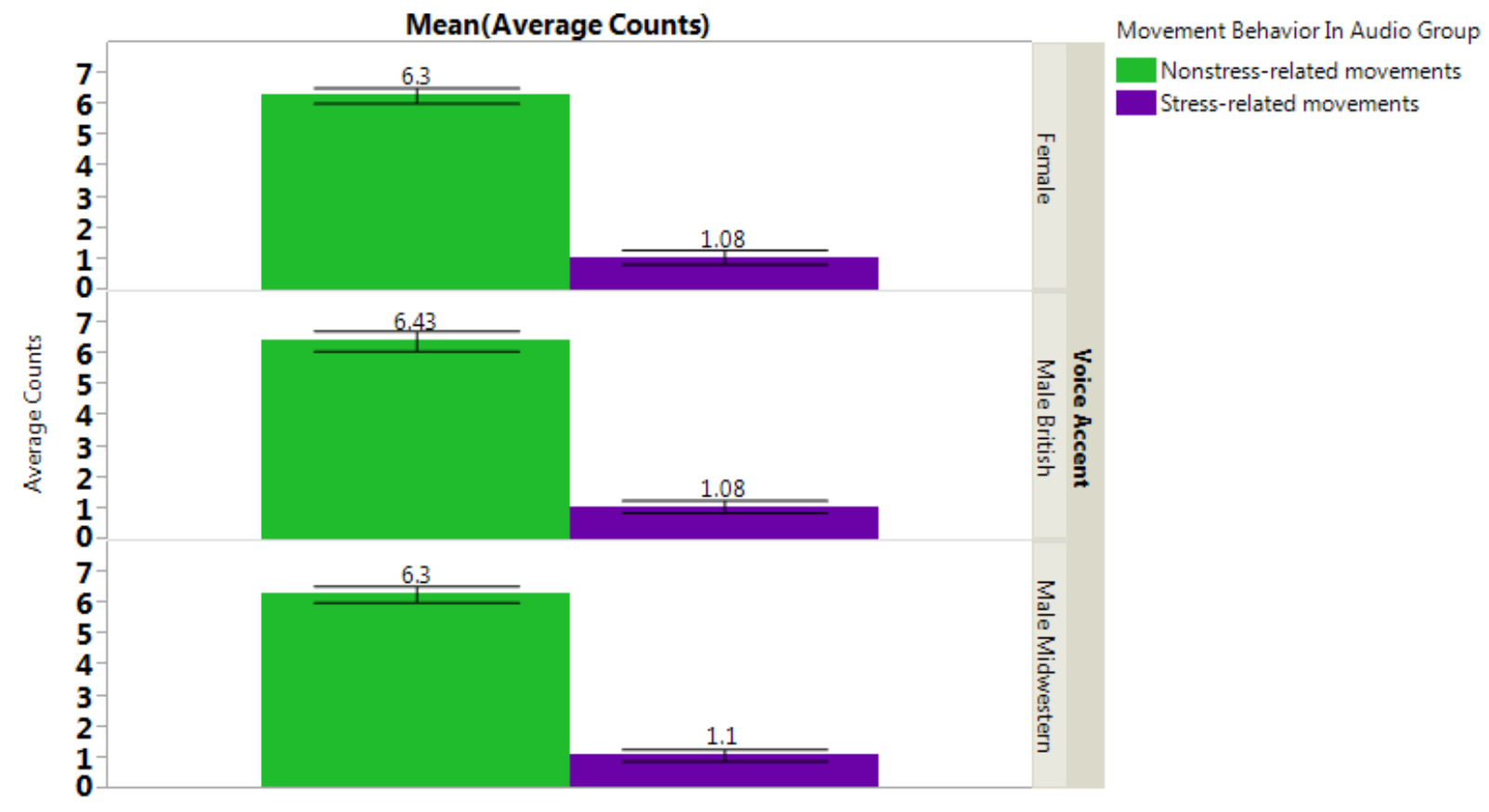

Figure 12. Average Number of Movement Types by Voice Variable in Bar Graph Form. This figure illustrates the average number of movement types (stress-related vs. nonstress-related) for each voice variable. It shows that there was no real difference in the amount of nonstress-related and stress-related movements exhibited by the dogs for the different voice variables. For every voice variable there were a higher amount of nonstress-related movements and fewer stress-related movements

\section{Room of Dogs as Experimental Units}

The dogs were divided into two experimental units ( $E U=1$ room) based on when they were exposed to the different treatments (audio vs. no audio). There were 2 groups, 2 behavior types (stress \& nonstress-related), and 6 sessions to give a total of 24 observations. The number of stress related and nonstress-related behaviors for each EU group session were averaged then that mean was used to perform a matched t-test between the treatment types (audio vs. no audio). The matched t-test revealed a large $\mathrm{F}$ ratio $(\mathrm{F}=553.8)$ and a small $\mathrm{p}$ value $(\mathrm{P}<.0001)$ for the mean difference which indicates that there is a significant difference between the average number of each behavior type 
exhibited by each EU for the treatment types $(\mathrm{P}=0.05)$. This supports the previous matched t-tests performed on the individual dogs. Figure 13 illustrates that for each EU there were a higher amount of stress-related behaviors in the no audio group and a higher amount of nonstress-related behaviors in the audio group.

\section{Table 9. Matched T-test for Experimental Units by Treatment. \\ This table shows the difference between the experimental units' (EU) behavioral types (stress-related $v s$. nonstress-related) for the treatment type (audio $v s$. no audio). The mean difference has a large $\mathrm{F}$ ratio $(\mathrm{F}=553.82)$ and a $\mathrm{p}$ value of $\mathrm{P}<.0001$. This indicates there was a significant difference between the average number of each behavior type exhibited by each EU for the treatment types $(\mathrm{P}=0.05)$.}

\section{Matched Pairs - with type as a grouping variable $(X)$ \\ Difference: No Audio means-Audio means}

\author{
No Audio means \\ Audio means \\ Mean Difference \\ Std Error \\ Upper 95\% \\ Lower 95\% \\ $\mathrm{N}$ \\ Correlation

\section{Across Groups} \\ Behavior type \\ Nonstress_related \\ Stress_related
}

Test Across Groups

Mean Difference

Mean Mean

4.5
4.49167
0.00833
0.8859
1.84095
-1.8243
24
-0.8576

t-Ratio

DF

Prob $>|t|$

Prob $>t$

Prob $<\mathrm{t}$

0.009407

23

0.9926

0.4963

0.5037

$\begin{array}{rrr}\text { Count } & \begin{array}{r}\text { Mean } \\ \text { Difference }\end{array} & \text { Mean Mean } \\ 12 & -4.158 & 4.2542 \\ 12 & 4.175 & 4.7375\end{array}$

$\begin{array}{rrr}\text { F Ratio } & \text { Prob }>\text { F } & \\ 553.8214 & <.0001^{*} \text { Within Pairs } & \text { Y Axis } \\ 3.9723 & 0.0588 \text { Among Pairs } & \text { X Axis }\end{array}$




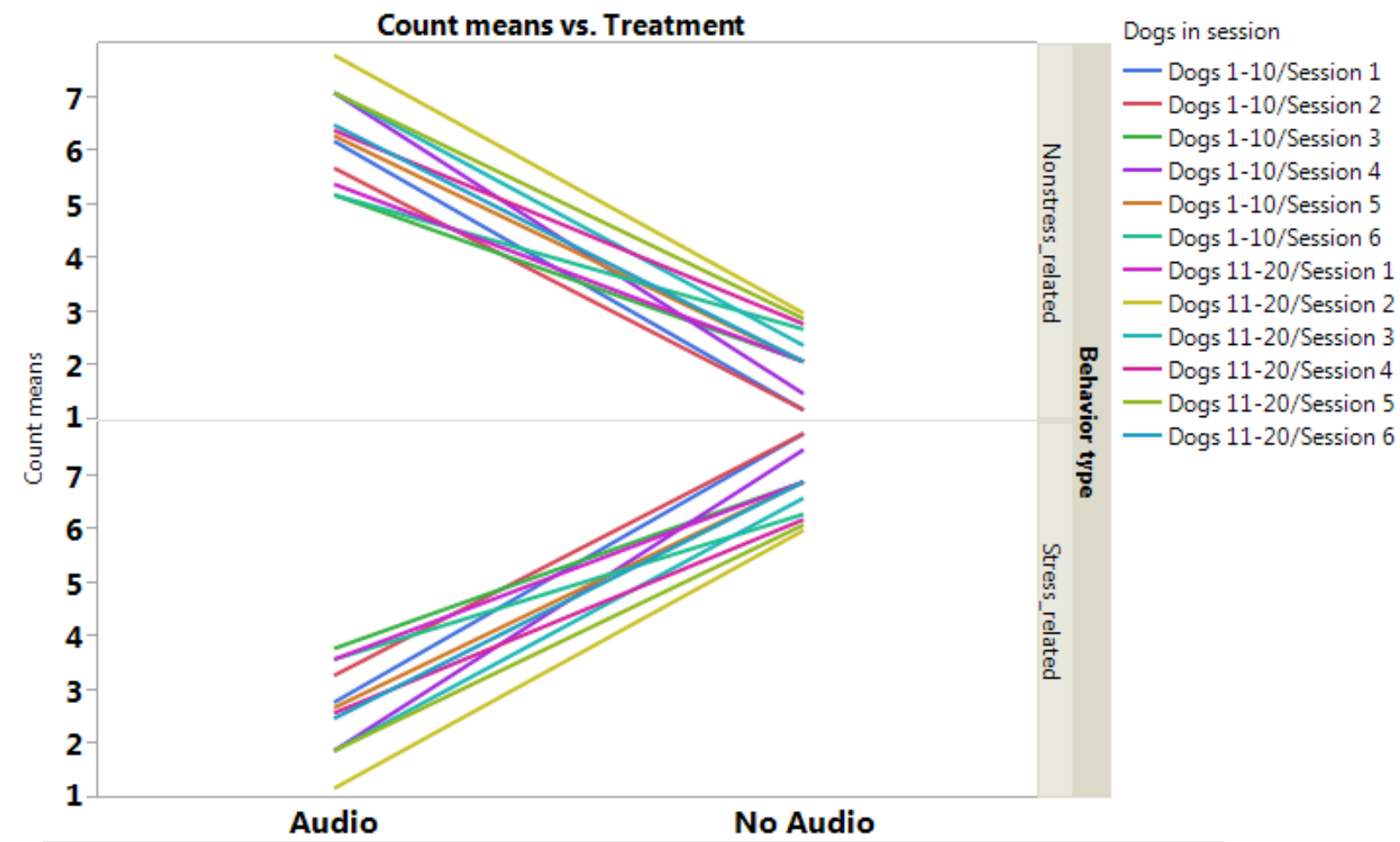

Figure 13. Average Number of Each Behavior Type per Experimental Units by Treatment. This figure illustrates the average number of each behavior type (stressrelated vs. nonstress-related) for each EU for each treatment type (audio vs. no audio). The graph shows an increase in stress-related behaviors for each EU in the no audio group and an increase in nonstress-related behaviors for each EU in the audio group.

\section{Individual Subjects Summaries}

Figures 14-15 show the recorded behavioral results for each individual dog. Each dog showed a decrease in the amount of stress-related behaviors when exposed to the audiobook stimulus. Dogs 1,18 and 19 showed the greatest difference in stress-related and nonstress-related behaviors observed for the audiobook sessions (Figure 14). Dogs 1, 18 and 19 had, on average, 7.6 nonstress-related behaviors to 1.4 stress-related behaviors per audiobook session (Figure 14). Dogs 9 and 13 showed the smallest differences observed for the audiobook sessions with, on average 5 nonstress-related behaviors to 4 stress-related behaviors per session (Figure 14). For the control group dogs 2 and 13 had the largest difference in stress-related and nonstress-related behaviors observed with, on average, 8.5 
stress-related behaviors to 0.5 nonstress-related behaviors per session (Figure 15). Dogs 6, 8 and 18 had the smallest differences with, on average, 6 stress-related behaviors to 3 nonstress-related behaviors per session (Figure 15).

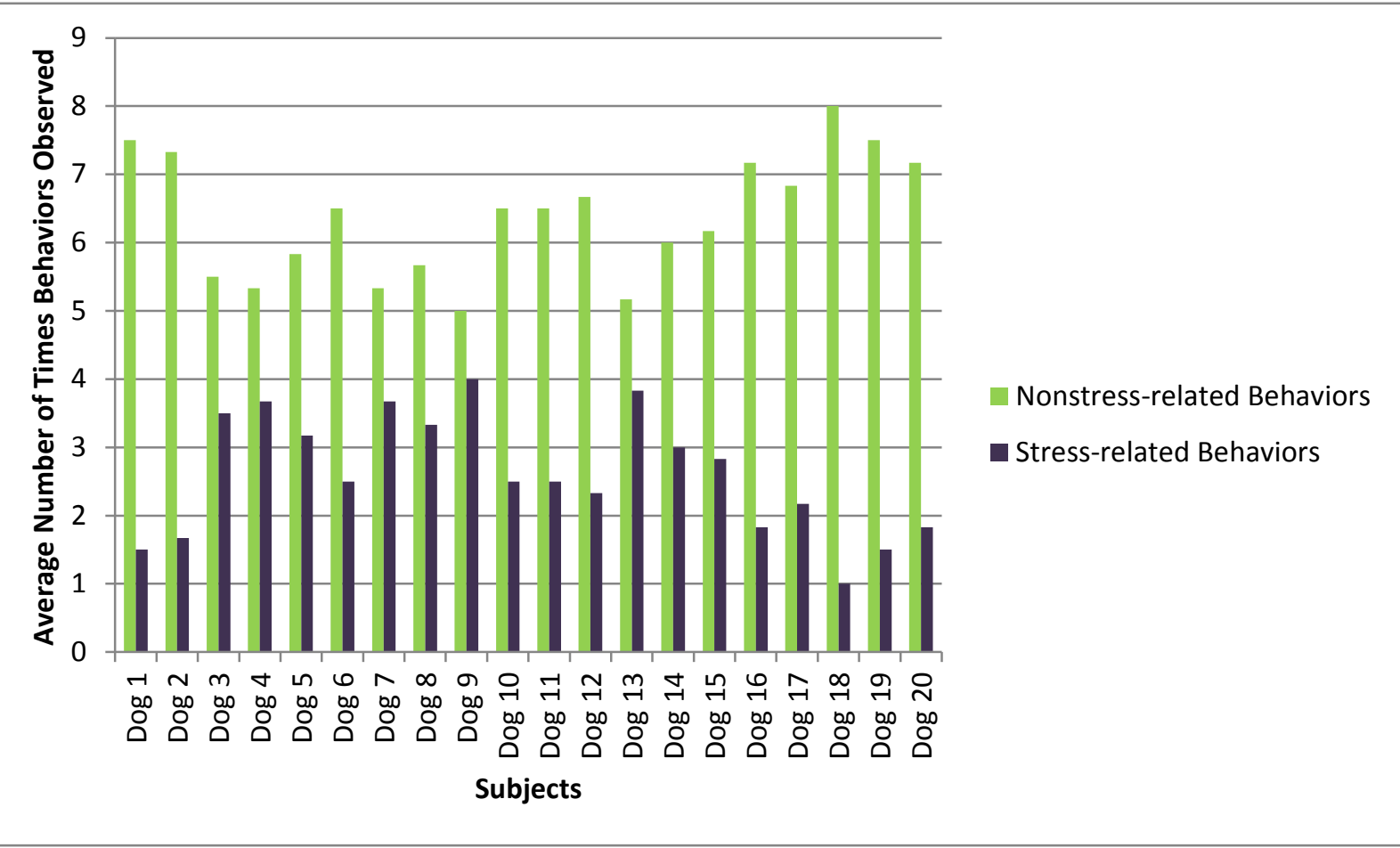

Figure 14. Behaviors Observed in Individual Subjects when Exposed to Audiobook Recording. The figure displays the behavioral results from each subject $(\mathrm{N}=20)$ when the audiobook recordings were played. 


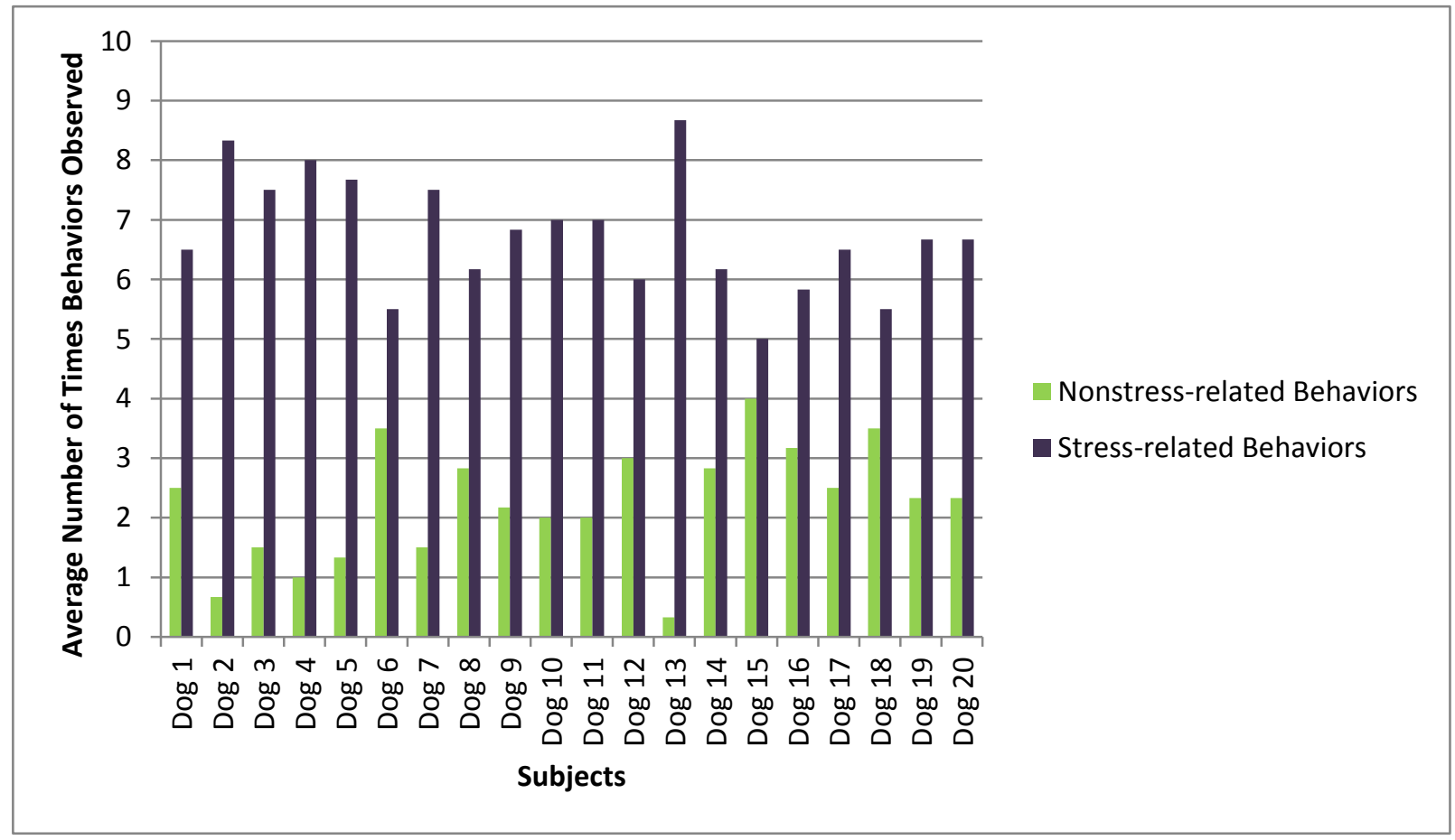

Figure 15. Behaviors Observed in Individual Subjects when Exposed No Audiobook Recording. The figure displays the behavioral results from each subject $(\mathrm{N}=20)$ when no audiobook recordings was played. 


\section{Chapter 5}

\section{Discussion}

Shelters are extremely stressful environments for dogs. The constant kenneling and lack of stimulation can lead to agitation, fearfulness or even aggression (Belpedio 2012). Dogs that remain in shelters for extended periods of time are highly prone to developing one of these behavioral issues (Belpedio 2012). The findings presented in this study suggest that the sound of the human voice decreases the behavioral indicators of stress in dogs housed in an animal shelter. A marked decrease in the amount of stress-related behaviors displayed was observed when comparing the control group to the experimental group that heard the recording. When the dogs were exposed to the recordings they were much more prone to lie down and sleep as compared to the control group. The control group had higher instances of pacing and a significant increase in barking. These findings are comparable to the music studies, which suggested that listening to classical music can decrease the amount of stress-related behaviors observed in dogs (Biele et al., 2012; Kogen et al., 2012).

The study did have a small sample size but by using a cross-over design it allowed the results to be statistically significant. The vast differences in dogs (i.e. breed, age, gender, neuter status) that come into animal shelters were a limitation. The age and gender of the dogs that participated in the study were able to be controlled for as the gender ratio and average age of the dogs were the same in both groups. The breed type was not able to be controlled for as there were difficulties in determining the exact breed combinations of the 
16 mixed-breed dogs. The neuter status was also not controlled for as there were only 2 neutered dogs in the study.

There were no significant differences between the behavioral reactions of the dogs to the variations in accent or vocal pitch of the narrator. This suggests that the dogs were responding to a human speaking to them and not simply reacting to a voice. Previous studies have shown that shelter dogs do become less stressed when they receive human interactions (Coppola et al., 2006). If hearing a recording of a human voice produces comparable nonstress-related behaviors to actual human contact then this could be an alternative tool for shelters to utilize.

Development of behavior issues such as kennel aggression can often lead to a dog having to be euthanized. Therefore it is in a shelter's interest to lower the amount of stress these dogs undergo on a day to day basis. Results from this study suggest that playing an audiobook recording for the kenneled dogs could provide a bit of comfort and relaxation. If the dogs spend more of their time in a relaxed state they will have less of a chance to showcase behaviors that are not seen as highly adoptable. In order to maximize the effectiveness of the audiobooks it should not be played continuously but rather rotated with other stress relieving stimuli such as classical music and lavender smells. This will ensure that the dogs will not become unaffected by the audio stimulus due to overuse. However, playing an audiobook more frequently throughout the day will help keep dogs engaged and relaxed.

One of the concerns of shelter workers related to dog behavior is the development of kennelitis (Donaldson 2000). As mentioned previously this behavior occurs when dogs 
have been kenneled excessively for an extended period of time with little to no physical or mental stimulation. This lack of contact for a social oriented animal such as a dog is detrimental to their behavior (Donaldson 2000). Using the audiobook recordings as a way to provide auditory stimulation could help reduce behaviors that are connected with kennelitis such as the pacing, fearfulness and barking.

Another benefit to using recordings of the human voice could be an improvement in a potential adopter's visitation experience. One of the biggest complaints of the general public is that animal shelters are too loud. There is scientific backing to this as noise levels in kennels are, on average, between 95-115 decibels (Siebert 2010). To put that in perspective The Occupational Safety and Health Administration deems anything above 85 decibels as a hazard hearing environment (Siebert 2010). If dogs are kept in a more relaxed state that results in less barking potential adopters are more likely to stay in the kennel area longer and visit with the available dogs. This could potentially lead to a higher number of adoptions.

The reading programs which have become increasingly popular in animal shelters now have further evidence to back their claims that reading to dogs can decrease stressrelated behaviors. The shelter dogs in these particular programs may be responding to both the presence of a person along with the sound of their voice. However by isolating the voice as the primary stimulus in the current study it does have an effect on the behavior of the kenneled dogs. Shelters that have a smaller volunteer basis could use the recorded audiobooks without having to bring in volunteer readers. 


\section{Chapter 6}

\section{Conclusion \& Recommendations}

The findings from this research study suggest that the human voice does have a calming effect on the behavioral indicators of stress exhibited by dogs in animal shelters. Dogs who were exposed to the audiobook recordings displayed a higher amount of nonstress-related behaviors (i.e. sitting quietly, laying down, sleeping, tail wagging and standing quietly) than the group who were not exposed. The dogs in the experimental group showed a reduction in barking as well. The accent or the vocal pitch (male vs. female) of the recording did not result in a change in the amount of stress-related behaviors observed. These findings could provide another low-cost tool for animal shelters to help promote nonstress-related and restful behaviors for dogs in their kennels. Further, a decrease in the amount of stress-related behaviors exhibited in dogs at animal shelters could lead to an increase in adoption rates.

Further research looking at the effect of the human voice on shelter dog's behaviors would be beneficial. This study was limited by a smaller sample size due to a high turnover rate within the shelter used. A larger sample size may help to see if there are significant differences in behavioral findings for different breeds or age groups. Also experimenting with a wider range of accents and vocal pitches could provide a better interpretation of what vocal range promotes the most relaxing behaviors. Researching the effects of the human voice in different stressful settings (i.e. home alone, vet offices, cars) could also show different ways that this auditory stimulus could help dogs 


\section{References}

Andics, Attila, Marta Gacsi, Tamas Farago, Anna Kis, and Adam Miklosi. "Voice-Sensitive

Regions in the Dog and Human Brain Are Revealed by Comparative FMRI." Current Biology 24.5 (2014): 574-78. Print.

ASPCA. "Saving Lives." SAFER FAQs. N.p., n.d. Web. 03 Apr. 2015.

Backus, Perry. "'Hamilton Kids Calm Shelter Cats and Dogs by Reading to Them." Missoulian: Missoula News and Resources for Western Montana. [Missoula] June 2013: Print.

Beerda, Bonne, Matthijs B.h Schilder, Jan A.r.a.m Van Hooff, Hans W De Vries, and Jan A. Mol. "Behavioural, Saliva Cortisol and Heart Rate Responses to Different Types of Stimuli in Dogs." Applied Animal Behaviour Science 58.3-4 (1998): 365-81. Web.

Beerda, Bonne, Matthijs B.h Schilder, Jan A.r.a.m Van Hooff, Hans W De Vries, and Jan A. Mol. "Chronic Stress in Dogs Subjected to Social and Spatial Restriction. I. Behavioral Responses." Physiology \& Behavior 66.2 (1999): 233-42. Web.

Belpedio, Camille. "Understanding Kennel Stress in Canines (Canis Lupus Familiaris)—A

Review of the Literature." Journal of Applied Companion Animal Behavior 4.1 (2012): 7-14. Web.

Biele, Heather. "Classical Music Strikes a Chord with Dogs in Colorado State Study." Dvm360. N.p., 18 Oct. 2012. Web. 
"Blue Buffalo Home 4 the Holidays Pet Adoption Campaign." Blue Buffalo Home 4 The Holidays. N.p., 2015. Web. 30 Apr. 2015.

Chappell, Kathryn. "Chronic Stress in Kennelling: Some Practical Considerations." Veterinary Times 07 June 2009: 28-31. Print.

Coppinger, Raymond, and Jule Zuccotti. "Kennel Enrichment: Exercise and Socialization of Dogs." Journal of Applied Animal Welfare Science 2.4 (1999): 281-96. Web.

Coppola, Crista L., Temple Grandin, and R. Mark Enns. "Human Interaction and Cortisol: Can Human Contact Reduce Stress for Shelter Dogs?" Physiology \& Behavior 87.3 (2006): 537-41. Web.

Dalla, Villa, S. Bernard, E. Di Fede, M. Podaliri, L. Candeloro, A. Di Nardo, C. Siracusa, and JA Serpell. "Behavioural and Physiological Responses of Shelter Dogs to Long-term Confinement." Vet. Ital. 49.2 (2013): 231-41. Print.

Dickens, Charles. Read by Simon Vance. A Tale of Two Cities (Unabridged Classics in Audio). Tantor Audio, 2008. CD.

Donaldson, Jean. "Behavior Problems And Long-Term Housing of Shelter Dogs." Behavior Problems and Long Term Housing. N.p., 2000. Web. 10 Mar. 2015.

Dwyer, Fleur, Pauleen C. Bennett, and Grahame J. Coleman. "Development of the Monash Dog Owner Relationship Scale (MDORS)." Anthrozoos: A Multidisciplinary Journal of The Interactions of People \& Animals 19.3 (2006): 243-56. Web.

Gácsi, Márta, Katalin Maros, Sofie Sernkvist, Tamás Faragó, and Ádám Miklósi. "Human Analogue Safe Haven Effect of the Owner: Behavioural and Heart Rate Response to Stressful Social Stimuli in Dogs." Ed. Allan V. Kalueff. PLoS ONE 8.3 (2013): E58475. Web. 
Handlin, Linda, Anne Nilsson, Mikael Ejdebäck, Eva Hydbring-Sandberg, and Kerstin UvnäsMoberg. "Associations between the Psychological Characteristics of the HumanDog Relationship and Oxytocin and Cortisol Levels." Anthrozoos: A Multidisciplinary Journal of The Interactions of People \& Animals 25.2 (2012): 215-28. Web.

Hennessy, Michael B., Angela Morris, and Fran Linden. "Evaluation of the Effects of a Socialization Program in a Prison on Behavior and Pituitary-adrenal Hormone Levels of Shelter Dogs." Applied Animal Behaviour Science 99.1-2 (2006): 157-71. Web.

Hennessy, Michael B., Michael T. Williams, Deborah D. Miller, Chet W. Douglas, and Victoria L. Voith. "Influence of Male and Female Petters on Plasma Cortisol and Behaviour: Can Human Interaction Reduce the Stress of Dogs in a Public Animal Shelter?" Applied Animal Behaviour Science 61.1 (1998): 63-77. Web.

Herron, M. E., T. M. Kirby-Madden, and L. K. Lord. "Effects of Environmental Enrichment on the Behavior of Shelter Dogs." Journal of the American Veterinary Medical Association 244.6 (2014): 687-92. Print.

Hoffman, Matthew. "Talking with Tone." Dogspeak: How to Understand Your Dog and Help Him Understand You. Emmaus, PA: Rodale, 1999. 158. Print.

Horváth, Zsuzsánna, Antal Dóka, and Ádám Miklósi. "Affiliative and Disciplinary Behavior of Human Handlers during Play with Their Dog Affects Cortisol Concentrations in opposite Directions." Hormones and Behavior 54.1 (2008): 107-14. Web. 
Kemp, A. H., and A. J. Guastella. "The Role of Oxytocin in Human Affect: A Novel Hypothesis." Current Directions in Psychological Science 20.4 (2011): 222-31. Web.

"Kennelitis." Saunders Comprehensive Veterinary Dictionary, 3 Ed. N.p., 2007. Web. 12 Mar. 2015.

Kogen, L., R. Schoenfeld-Tacher, and A. Simon. "Behavioral Effect of Auditory Stimulation on Kenneled Dogs." Journal of Veterinary Behavior 7 (2012): 268-75. Web.

Lacey, Martha De. "Stories for Spaniels, Tales for Terriers: Shakespeare Actor Simon Callow Narrates World's First Bedtime Audiobook for Dogs, Scientifically Proven to Calm Stressed Pets." Mail Online. Associated Newspapers, 05 Nov. 2012. Web. 12 Mar. 2015.

Merkies. K, H. Macgregor, M. Ouimette, E. Bogart, and K. Miraglia. "Does the Human Voice Have a Calming Effect on Horses?" Journal of Equine Veterinary Science 33.5 (2013): 368. Web.

Normando, Simona, Livio Corain, Martina Salvadoretti, Lieve Meers, and Paola Valsecchi. "Effects of an Enhanced Human Interaction Program on Shelter Dogs' Behaviour Analysed Using a Novel Nonparametric Test." Applied Animal Behaviour Science 116.2-4 (2009): 211-19. Web.

Patronek, G. J., L. T. Glickman, A. M. Beck, G. P. McCabe, and C. Ecker. "Risk Factors for Relinquishment of Dogs to an Animal Shelter." J Am Vet Med Assoc. (1999): n. pag. PubMed. Web.

"The PEDIGREE® Feeding Project." Adopt Rescue Dogs Through The PEDIGREE® Foundation. N.p., 2015. Web. 30 Apr. 2015. 
"Pet Overpopulation." Pet Overpopulation. American Humane Association, 2013. Web. 27 Feb. 2015.

Poehler, Amy. Yes Please. Harper Audio, 2014. CD.

Protopopova, Alexandra et al. "In-Kennel Behavior Predicts Length of Stay in Shelter Dogs." Ed. Peter James Hansen. PLoS ONE 9.12 (2014): e114319.PMC. Web. 12 Mar. 2015. Pullen, Anne J., Ralph J.n. Merrill, and John W.s. Bradshaw. "The Effect of Familiarity on Behaviour of Kennel Housed Dogs during Interactions with Humans." Applied Animal Behaviour Science 137.1-2 (2012): 66-73. Web.

Ratcliffe, Victoria F., and David Reby. "Orienting Asymmetries in Dogs' Responses to Different Communicatory Components of Human Speech." Current Biology 24.24 (2014): 2908-912. Web.

Rooney, Nicola J., John W.s Bradshaw, and Ian H. Robinson. "A Comparison of Dog-dog and Dog-human Play Behaviour." Applied Animal Behaviour Science 66.3 (2000): 23548. Web.

Seibert, Phil. "Regulations You Need to Know: OSHA." DVM 360. N.p., Aug. 2010. Web. Serpell, James. The Domestic Dog: Its Evolution, Behaviour, and Interactions with People. Cambridge: Cambridge UP, 1995. Print.

"The Shelter Pet Project By the Numbers - And Something More ." The Shelter Pet Project by the Numbers. Maddie's Fund, 23 Sept. 2013. Web. 12 Mar. 2015.

Shiverdecker, Matthew D., Patricia A. Schiml, and Michael B. Hennessy. "Human Interaction Moderates Plasma Cortisol and Behavioral Responses of Dogs to Shelter Housing." Physiology \& Behavior 109 (2013): 75-79. Web. 
Stephen, Jacqueline M., and Rebecca A. Ledger. "An Audit of Behavioral Indicators of Poor Welfare in Kenneled Dogs in the United Kingdom." Journal of Applied Animal Welfare Science 8.2 (2005): 79-95. Web.

Stevenson, Robert Louis. Read by Scott Brick. The Strange Case of Dr. Jekyll \& Mr. Hyde. Tantor Audio, 2006, CD.

Titulaer, Mieke, Emily J. Blackwell, Michael Mendl, and Rachel A. Casey. "Cross Sectional Study Comparing Behavioural, Cognitive and Physiological Indicators of Welfare between Short and Long Term Kennelled Domestic Dogs." Applied Animal Behaviour Science 147.1-2 (2013): 149-58. Web.

Tsigos, Constantine, and George P. Chrousos. "Hypothalamic-pituitary-adrenal Axis, Neuroendocrine Factors and Stress." Journal of Psychosomatic Research 53.4 (2002): 865-71. Web.

Walker, Jessica, Clive Phillips, and Natalie Waran. "The Effect of Conspecific Removal on the Behaviour and Physiology of Pair-housed Shelter Dogs." Applied Animal Behaviour Science 158 (2014): 46-56. Print.

Wells, D., L. Graham, and P. G. Hepper. "The Influence of Auditory Stimulation on the Behaviour of Dogs Housed in a Rescue Shelter." Animal Welfare 11.2 (2002): 38593. Web.

Wells, Deborah L., and Peter G. Hepper. "The Influence of Environmental Change on the Behaviour of Sheltered Dogs." Applied Animal Behaviour Science 68.2 (2000): 151-62. Web. 


\section{Vita}

Juliana Marie Hypes was born in Charleston, West Virginia. She completed her undergraduate degree in 2013 at West Virginia University in Morgantown, West Virginia in Animal and Nutritional Science. The purpose of her Master of Science in Animal and Nutritional Sciences was to further knowledge of animal behavior. She has been a volunteer at the Kanawha Charleston Humane Association throughout her college career and will be working as their onsite behaviorist. 